\title{
Mexico city aerosol analysis during MILAGRO using high resolution aerosol mass spectrometry at the urban supersite (T0) - Part 2: Analysis of the biomass burning contribution and the non-fossil carbon fraction
}

A. C. Aiken ${ }^{1,2}$, B. de Foy ${ }^{3}$, C. Wiedinmyer ${ }^{4}$, P. F. DeCarlo ${ }^{2,5}{ }^{*}$, I. M. Ulbrich ${ }^{1,2}$, M. N. Wehrli ${ }^{6}$, S. Szidat ${ }^{6}$, A. S. H. Prevot ${ }^{7}$, J. Noda ${ }^{8, * *}$, L. Wacker ${ }^{9}$, R. Volkamer ${ }^{1,2}$, E. Fortner ${ }^{10}$, J. Wang $^{11}$, A. Laskin ${ }^{12}$, V. Shutthanandan ${ }^{12}$, J. Zheng ${ }^{10}$, R. Zhang ${ }^{10}$, G. Paredes-Miranda ${ }^{13}$, W. P. Arnott ${ }^{13}$, L. T. Molina ${ }^{14}$, G. Sosa ${ }^{15}$, X. Querol ${ }^{16}$, and J. L. Jimenez ${ }^{1,2}$

${ }^{1}$ Department of Chemistry and Biochemistry, University of Colorado, Boulder, CO, USA

${ }^{2}$ Cooperative Institute for Research in the Environmental Sciences (CIRES), University of Colorado, Boulder, CO, USA

${ }^{3}$ Saint Louis University, St. Louis, MO, USA

${ }^{4}$ National Center for Atmospheric Research, Boulder, CO, USA

${ }^{5}$ Department of Atmospheric and Oceanic Sciences, University of Colorado, Boulder, CO, USA

${ }^{6}$ Department of Chemistry and Biochemistry, University of Bern, Berne, Switzerland

${ }^{7}$ Laboratory of Atmospheric Chemistry, Paul Scherrer Institut, Villigen, Switzerland

${ }^{8}$ Department of Chemistry, Atmospheric Science, University of Gothenburg, Gothenburg, Sweden

${ }^{9}$ Institute for Particle Physics, ETH Hönggerberg, Zurich, Switzerland

${ }^{10}$ Texas A\&M University, College Station, TX, USA

${ }^{11}$ Brookhaven National Laboratory, Upton, NY, USA

${ }^{12}$ Pacific Northwest National Laboratory, Richland, USA

${ }^{13}$ Dept. of Physics, University of Nevada and the Desert Research Institute, Reno, NV, USA

${ }^{14}$ Molina Center for Energy and the Environment and Massachusetts Institute of Technology, USA

${ }^{15}$ Instituto Mexicano del Petróleo, Mexico City, Mexico

${ }^{16}$ IDAEA, Consejo Superior de Investigaciones Científicas, Barcelona, Spain

*now at: Paul Scherrer Institut, Switzerland

${ }^{* *}$ now at: the Rakuno Gakuen University, Japan

Received: 14 September 2009 - Published in Atmos. Chem. Phys. Discuss.: 2 December 2009

Revised: 20 April 2010 - Accepted: 4 May 2010 - Published: 16 June 2010

\begin{abstract}
Submicron aerosol was analyzed during the MILAGRO field campaign in March 2006 at the T0 urban supersite in Mexico City with a High-Resolution Aerosol Mass Spectrometer (AMS) and complementary instrumentation. Positive Matrix Factorization (PMF) of high resolution AMS spectra identified a biomass burning organic aerosol (BBOA) component, which includes several large plumes that appear to be from forest fires within the region. Here, we show
\end{abstract}

Correspondence to: J. L. Jimenez (jose.jimenez@colorado.edu) that the AMS BBOA concentration at T0 correlates with fire counts in the vicinity of Mexico City and that most of the BBOA variability is captured when the FLEXPART model is used for the dispersion of fire emissions as estimated from satellite fire counts. The resulting FLEXPART fire impact factor (FIF) correlates well with the observed BBOA, acetonitrile $\left(\mathrm{CH}_{3} \mathrm{CN}\right)$, levoglucosan, and potassium, indicating that wildfires in the region surrounding Mexico City are the dominant source of BBOA at T0 during MILAGRO. The impact of distant BB sources such as the Yucatan is small during this period. All fire tracers are correlated, with BBOA and levoglucosan showing little background, acetonitrile having

Published by Copernicus Publications on behalf of the European Geosciences Union. 
a well-known tropospheric background of $\sim 100-150 \mathrm{pptv}$, and $\mathrm{PM}_{2.5}$ potassium having a background of $\sim 160 \mathrm{ng} \mathrm{m}^{-3}$ (two-thirds of its average concentration), which does not appear to be related to BB sources.

We define two high fire periods based on satellite fire counts and FLEXPART-predicted FIFs. We then compare these periods with a low fire period when the impact of regional fires is about a factor of 5 smaller. Fire tracers are very elevated in the high fire periods whereas tracers of urban pollution do not change between these periods. Dust is also elevated during the high BB period but this appears to be coincidental due to the drier conditions and not driven by direct dust emission from the fires. The AMS oxygenated organic aerosol (OA) factor (OOA, mostly secondary OA or SOA) does not show an increase during the fire periods or a correlation with fire counts, FLEXPART-predicted FIFs or fire tracers, indicating that it is dominated by urban and/or regional sources and not by the fires near the MCMA.

A new ${ }^{14} \mathrm{C}$ aerosol dataset is presented. Both this new and a previously published dataset of ${ }^{14} \mathrm{C}$ analysis suggest a similar BBOA contribution as the AMS and chemical mass balance (CMB), resulting in 13\% higher non-fossil carbon during the high vs. low regional fire periods. The new dataset has $\sim 15 \%$ more fossil carbon on average than the previously published one, and possible reasons for this discrepancy are discussed. During the low regional fire period, $38 \%$ of organic carbon (OC) and 28\% total carbon (TC) are from nonfossil sources, suggesting the importance of urban and regional non-fossil carbon sources other than the fires, such as food cooking and regional biogenic SOA.

The ambient $\mathrm{BBOA} / \Delta \mathrm{CH}_{3} \mathrm{CN}$ ratio is much higher in the afternoon when the wildfires are most intense than during the rest of the day. Also, there are large differences in the contributions of the different OA components to the surface concentrations vs. the integrated column amounts. Both facts may explain some apparent disagreements between BB impacts estimated from afternoon aircraft flights vs. those from 24-h ground measurements.

We show that by properly accounting for the non-BB sources of $\mathrm{K}$, all of the BB PM estimates from MILAGRO can be reconciled. Overall, the fires from the region near the MCMA are estimated to contribute $15-23 \%$ of the OA and 7-9\% of the fine PM at T0 during MILAGRO, and 2-3\% of the fine PM as an annual average. The 2006 MCMA emissions inventory contains a substantially lower impact of the forest fire emissions, although a fraction of these emissions occur just outside of the MCMA inventory area.

\section{Introduction}

Fine particles have important effects on human health (Dockery et al., 1993), the radiative forcing of climate (IPCC, 2007), regional visibility (Watson, 2002), and deposition to ecosystems, crops, and buildings (Likens et al., 1996). Very large urban areas, known as megacities, are large sources of fine particles for the regional and global environment (Madronich, 2006; Lawrence et al., 2007). The MILAGRO field campaign which took place during March 2006 used multiple sites and mobile platforms to assess pollutant emissions, and evolution in and around Mexico City (Molina et al., 2007). MILAGRO builds upon several smaller international campaigns conducted in Mexico City, including IMADA-AVER (Edgerton et al., 1999) and MCMA-2003 (Salcedo et al., 2006; Molina et al., 2007).

Open biomass burning (BB) is a major global source of fine particles and particle precursors, although a precise quantification of BB emissions and impacts is difficult due to poorly known fire locations, fuel consumption, emission factors, dispersion, and secondary aerosol formation (Andreae and Merlet, 2001; Bond et al., 2004; de Gouw and Jimenez, 2009; Hallquist et al., 2009). Previous reports (Bravo et al., 2002; Salcedo et al., 2006; Molina et al., 2007) as well as reports from MILAGRO (Yokelson et al., 2007; DeCarlo et al., 2008, 2010; Kleinman et al., 2008; Moffet et al., 2008a; Stone et al., 2008; Aiken et al., 2009; Crounse et al., 2009; de Gouw et al., 2009; Stone et al., 2009) indicate that open BB emissions can at times be an important contributor to fine PM and especially organic aerosol (OA) concentrations in Mexico City during the warm dry season, with an even larger impact to the outflow from the Central Mexican Plateau.

As part of MILAGRO we deployed a high-resolution timeof-flight aerosol mass spectrometer (HR-ToF-AMS) and complementary instrumentation to the T0 site near downtown Mexico City. In a first paper we reported on the overall fine particle composition at this site, of which about half was due to OA (Aiken et al., 2009), similar to several previous campaigns in Mexico City (Chow et al., 2002; Vega et al., 2004; Salcedo et al., 2006) and also similar to aircraft data from MILAGRO (DeCarlo et al., 2008, 2010; Kleinman et al., 2008).

In Aiken et al. (2009) the results of source/component apportionment of the OA concentrations using Positive Matrix Factorization (PMF) of the high-resolution AMS data were reported, which compare well to those from chemical mass balance of organic molecular markers (CMB-OMM) previously published by Stone et al. (2008). Secondary organic aerosols (SOA), primary emissions from combustion sources such as traffic (urban POA), and biomass burning OA (BBOA) are the major contributors to the OA concentration at T0 according to both methods. CMB-OMM and PMFAMS report average contributions of BBOA to total OA at T0 of $12 \%$ and $16 \%$, respectively. 
Querol et al. (2008) report an estimate of about 10\% BB contribution to total $\mathrm{PM}_{2.5}$ at T0 (or about $\sim 17 \%$ of the OA). Liu et al. (2009) report that biomass burning contributed to a small fraction $(0-8 \%)$ of submicron particle mass at the downtown SIMAT site, several miles south of T0, while Gilardoni et al. (2009) report an upper limit of 33-39\% of the organic carbon (OC) due to $\mathrm{BB}$ at the same site. Moffet et al. (2008a) report a $\sim 40 \%$ contribution of particles containing $\mathrm{K}$ to the particle number concentration at the upper end of the accumulation mode at T0. de Gouw et al. (2009) report that the $\mathrm{BB}$ impact at the suburban site $\mathrm{T} 1$ was not dominant (6-38\% of organic carbon, with most days below 20\%) and perhaps not dissimilar from previous observations from the same group in the Northeast US.

Aircraft studies encompassing wider regional scales around Mexico City report higher fractional contributions (BBOA/OA) of the order of 50\% aloft and $25 \%$ near the surface during several afternoon flights (Yokelson et al., 2007; Crounse et al., 2009; DeCarlo et al., 2010). 3D model studies overpredict BBOA downwind of some very large fires but underpredict the primary BBOA concentrations in the urban area during the early morning (Fast et al., 2009; Hodzic et al., 2009) and predict a small contribution of BB emissions to SOA concentrations over the urban area from either traditional VOC precursors or non-traditional semi- and intermediate volatility precursors (Hodzic et al., 2009, 2010). Given the variations in some of these estimates and the potential limitations of the different apportionment methods to estimate BB emissions, it is of great interest to explore this topic in greater depth using additional techniques.

Analysis of the non-fossil carbon fraction is a powerful technique which characterizes the total OC concentration arising from non-fossil carbon sources, which include biogenic SOA, BB, and also some urban sources such as food cooking, tire wear, biofuel use, trash burning, tilemaking and adobe brick production (Hildemann et al., 1994; Raga et al., 2001). Marley et al. (2009) report that 45$78 \%$ of the total particulate carbon at $\mathrm{T} 0 \quad(\mathrm{TC}=\mathrm{EC}+\mathrm{OC}$; $\mathrm{EC}=$ elemental carbon and $\mathrm{OC}=$ organic carbon) arises from non-fossil sources. However, Marley et al. (2009) did not account for the enrichment of ${ }^{14} \mathrm{C}$ of wood due to nuclear bomb radiocarbon ( $+16 \%$ for wood) (Szidat et al., 2009), leading to an overestimate of the non-fossil carbon fraction under conditions impacted by forest fires.

Previous results have found similar fractions (31-63\%) of modern TC in other urban background locations (Hildemann et al., 1994; Szidat et al., 2006; Zheng et al., 2006; Weber et al., 2007), although the mix of sources that results in the measured modern carbon fraction in urban areas is often unclear (e.g. Weber et al., 2007; Fast et al., 2009). Since the fraction of modern carbon reported by Marley et al. (2009) for T0 is much higher than the contribution of BB to OC estimated with any measurement or modeling method at the surface during MILAGRO, it is of interest to further explore this topic and characterize the sources potentially contributing to the non-fossil and fossil OC fractions.

In this paper, we use ground-based measurements inside the Mexico City Metropolitan Area (MCMA) at the T0 Supersite to further investigate the impact of BB sources and the OA non-fossil carbon fraction at the T0 supersite. The paper is structured as follows: Sect. 2 presents the methods used in this study and not already described by Aiken et al. (2009); Sect. 3.1 presents the results of FLEXPART lagrangian dispersion modeling of the impact from forest fires; Sect. 3.2 compares the different BB gas-phase and particlephase tracers and dispersion model results at T0; Sect. 3.3 compares the concentrations of $\mathrm{OA}$ components and many other species during periods with high versus low open BB activity as identified by fire counts and modeled fire impact factors (FIFs); and Sect. 3.4 presents new modern carbon analyses for T0 samples and compares them with previouslypublished results and results from other techniques. Finally, Sect. 4 discusses the results, evaluates the reasons for the differences between in-city ground-based and regional-scale aircraft studies and summarizes the different estimates of BB impacts at $\mathrm{T} 0$.

\section{Methods}

\subsection{General}

An introduction to the MILAGRO study and the sites used can be found in previous publications (Fast et al., 2007; Aiken et al., 2009; Molina et al., 2010). Aerosol data and samples were collected at the T0 Supersite $\sim 28 \mathrm{~m}$ above ground level, from 10 March 2006 to 31 March 2006, unless otherwise stated. T0 was located at the Instituto Mexicano del Petroleo (IMP, $19^{\circ} 29^{\prime} 23^{\prime \prime} \mathrm{N}, 9^{\circ} 08^{\prime} 55^{\prime \prime} \mathrm{W}, 2240 \mathrm{~m}$ altitude, $\sim 780$ mbar), $9 \mathrm{~km} \mathrm{NNW}$ of the MCMA center. The main focus of this work is the data acquired with a highresolution time-of-flight aerosol mass spectrometer (HRToF-AMS, abbreviated as AMS hereafter; Aerodyne Research, Billerica, MA), which has been described in detail previously (DeCarlo et al., 2006; Canagaratna et al., 2007). Further details on sampling and analysis procedures and intercomparisons with collocated instruments, as well as the experimental details for other data used in this work are described in the companion paper (Aiken et al., 2009).

PMF analysis of the high-resolution spectra identified hydrocarbon-like OA (HOA), oxygenated OA (OOA), BBOA, and a local amine-containing OA source (LOA). Observations from this study (Aiken et al., 2009) and many other studies in Mexico City (Volkamer et al., 2006, 2007; Herndon et al., 2008; Dzepina et al., 2009; Fast et al., 2009; Hodzic et al., 2009, 2010; Tsimpidi et al., 2010) and elsewhere (e.g. Zhang et al., 2005a, b; Lanz et al., 2007; Zhang et al., 2007; Docherty et al., 2008; Nemitz et al., 2008; Ulbrich et al., 2009) support the dominant association of HOA with urban POA and of OOA with SOA. An important fraction 
of HOA generally arises from vehicle exhaust, but this component may include sources such as trash burning, as trash contains a high fraction of plastic in Mexico City (Christian et al., 2010) and the spectrum of plastic burning is very similar to that of vehicle exhaust in the HR-ToF-AMS (Mohr et al., 2009). Note that although multiple OOAs (e.g. OOA1, OOA-2) have been identified in several studies (e.g. Lanz et al., 2007; Zhang et al., 2007; Aiken et al., 2008; Nemitz et al., 2008; Ulbrich et al., 2009), these more often seem to correspond to fresh vs. aged SOA, and the contribution of different SOA precursors such as biogenics, aromatics, etc. is generally not resolvable at present with electron impact AMS data alone (Jimenez et al., 2009; Ng et al., 2010; Heald et al., 2010). Meat cooking OA may be apportioned as HOA and/or BBOA due to the similarities of HR spectra from that source to HOA and BBOA spectra (Mohr et al., 2009).

The aerosol data is reported in $\mu \mathrm{g} \mathrm{m}^{-3}$ at local ambient pressure and temperature conditions (denoted as $\mu \mathrm{g} \mathrm{am}^{-3}$ for clarity). Note that to convert to STP (1 atm, $273 \mathrm{~K}, \mu \mathrm{g} \mathrm{sm}^{-3}$ ), the particle concentrations reported need to be multiplied by $\sim 1.42$, while gas-phase measurements in mixing ratio units (ppbv, pptv) are invariant. All measurements are reported in local standard time (LST), equivalent to US CST and UTC minus $6 \mathrm{~h}$, and the same as local time during the campaign.

\subsection{Fire/biomass burning impact analysis}

Daily satellite fire location and counts (Justice et al., 2002; Giglio et al., 2003) were acquired from MODIS instruments aboard the NASA AQUA and TERRA satellites from the MODIS Hotspot/Active Fire Detections (http://maps. geog.umd.edu), each having two overpasses a day (AQUA: 02:00-03:00 and 13:00-15:00 LST; TERRA: 10:00-12:00 and 22:00-23:00 LST) and with $\sim 1 \mathrm{~km}$ resolution imaging. Fire count data were also obtained from the NOAA GOES data as reported by FLAMBE (http://www.nrlmry.navy.mil/ flambe/index.html). GOES fire counts have less spatial resolution than those from MODIS but have the advantage of 24-h coverage with high temporal resolution ( $\sim 15-30 \mathrm{~min}$.). The presence of clouds may result in a low bias in fire detection. However, clouds are also associated with precipitation, increased humidity and reduced radiation, which also reduce the probability of fire occurrence. A recent satellite study showed that the probability of a fire occurring during a cloudy period in the Amazon was only 1/4-1/3 of that during a non-cloudy period, which indicates that the bias arising from this effect is small (Schroeder et al., 2008).

Satellite fire count data were used in conjunction with emission and dispersion modeling to estimate the BB impact from fires in Mexico as a function of time at the T0 Supersite. Daily emission estimates of $\mathrm{CO}(\mathrm{g})$ were developed from the satellite fire detections using the methods described by Wiedinmyer et al. (2006). The daily emission estimates were assigned a diurnal profile based on the GOES fire count data. Two scenarios were used, with emissions taking place either from 12:00-20:00 LST or from 14:00-24:00 LST. Limiting fires to the highest GOES quality assurance flag results in the later starting time for the second scenario. The later finishing time was chosen to account for smoldering fires which continue emitting into the night even though they can no longer be detected by satellite imaging due to low infrared emission.

Forward trajectories were modeled with the Lagrangian stochastic particle paths calculated by FLEXPART (Stohl et al., 2005) using meteorological fields simulated with the Weather Research Forecast (WRF) mesoscale meteorology model (Skamarock et al., 2005) as described in de Foy et al. (2009). Particle tracers are released between 0 and $50 \mathrm{~m}$ above ground level in proportion to the $\mathrm{CO}$ emissions, and consistent with the low buoyancy observed for fires around Mexico City during MILAGRO (R. Yokelson, personal communication, 2009). The number of particles released in the model varied from day to day with maxima of 13048 particles released from 163 fires for the whole modeling domain (which encompasses most of Mexico) and 2943 particles from 19 fires for the MCMA basin. FLEXPART modeling of emissions from the Tula industrial complex showed good agreement with observed $\mathrm{SO}_{2}$ and $\mathrm{NO}_{2}$ columns during MILAGRO, supporting the quality of the dispersion predictions from this method for the Mexico City region (Rivera et al., 2009).

\subsection{Quantification of ${ }^{14} \mathrm{C}$ in aerosol samples}

We present new ${ }^{14} \mathrm{C}$ data not published elsewhere that were analyzed by the University of Bern/Paul Scherrer Institut (PSI)/ETH-Zurich. Four 24-h filters were collected for ${ }^{14} \mathrm{C}$ analysis at T0 during continuous AMS sampling: (1) 21/3 09:04 a.m.-22/3 09:05 a.m., (2) 22/3 09:20 a.m.-23/3 09:20 a.m., (3) 26/3 09:40 a.m.-27/3 09:40 a.m., (4) 29/3 11:04 a.m.-30/3 11:05 a.m. The filters were collected with a HiVol sampler using a $\mathrm{PM}_{10}$ inlet on the roof of Bldg. 20, about $100 \mathrm{~m}$ from the AMS sampling location and at about the same height above the ground. After collection they were wrapped in aluminum foil, packed in air-tight plastic bags, and stored at $-20^{\circ} \mathrm{C}$. During transportation, the filter samples experienced ambient temperatures for $48 \mathrm{~h}$. The concentrations of OC and EC on the filters were determined with a commercial thermo-optical transmission instrument (Sunset Laboratory, Tigard, OR, USA).

For determining the ${ }^{14} \mathrm{C} /{ }^{12} \mathrm{C}$ isotopic ratio, the total carbon mass was apportioned into OC, water-insoluble OC (WIOC), and $\mathrm{EC}$ from the quartz fiber filters for ${ }^{14} \mathrm{C}$ measurement using a step-wise process (Szidat et al., 2004b). The details of the chemical separation are described elsewhere (Szidat et al., 2004a, 2006, 2009) Briefly, OC is oxidized at $340^{\circ} \mathrm{C}$ in a stream of pure oxygen. For analysis of the WIOC, the water-soluble compounds are removed by water extraction. The remaining carbon on the filter is then treated as the OC separation. The level of water-soluble OC (WSOC) is determined by subtraction of WIOC from OC. 
$\mathrm{EC}$ is then oxidized at $650^{\circ} \mathrm{C}$ after the complete removal of $\mathrm{OC}$ and interfering water-soluble inorganic compounds, which is carried out by extraction with diluted hydrochloric acid and water followed by pre-heating at $390^{\circ} \mathrm{C}$ for $4 \mathrm{~h}$. The $\mathrm{CO}_{2}(\mathrm{~g})$ evolving from $\mathrm{OC}$, WIOC, and EC is cryo-trapped and sealed in ampoules for ${ }^{14} \mathrm{C}$ measurement, which were performed on carbon amounts of 10-30 $\mu \mathrm{g}$ with accelerator mass spectrometry at ETH-Zurich. For the analysis the $\mathrm{CO}_{2}(\mathrm{~g})$ was mixed with $\mathrm{He}(\mathrm{g})$ and transferred into a custombuilt cesium sputter gas ion source of the $200 \mathrm{kV}$ miniradiocarbon dating system MICADAS (Ruff et al., 2007, 2010).

From the isotopic measurements, fractions were apportioned into fossil $\mathrm{EC}\left(\mathrm{EC}_{\mathrm{f}}\right)$, nonfossil $\mathrm{EC}\left(\mathrm{EC}_{\mathrm{nf}}\right)$, fossil OC $\left(\mathrm{OC}_{\mathrm{f}}\right)$, and non-fossil $\mathrm{OC}\left(\mathrm{OC}_{\mathrm{nf}}\right) . \mathrm{OC}_{\mathrm{nf}}$ is further divided among biomass burning non-fossil $\mathrm{OC}\left(\mathrm{OC}_{\mathrm{bbnf}}\right)$ and other non-fossil OC $\left(\mathrm{OC}_{\mathrm{onf}}\right)$ using the methodology of Szidat et al. (2009). $\mathrm{OC}_{\mathrm{bbnf}}$ is calculated from $\mathrm{EC}_{\mathrm{nf}}$ using an estimated $\mathrm{OC} / \mathrm{EC}$ ratio, as $\mathrm{OC}_{\mathrm{bbnf}}=\mathrm{EC}_{\mathrm{nf}} \times(\mathrm{OC} / \mathrm{EC})_{\mathrm{bb}}$. We use the average OC/EC value of $9.1 \pm 4.6$ (std. dev.) from values reported for temperate savannas by Reid et al. (Reid et al., 2005). However the range of variability of this parameter spans more than an order-of-magnitude, and ranges between 1.9 and 33 (averaging 11.1 \pm 9.3 ) for 21 studies of open burning reviewed by Reid et al. (2005). The average and range of open burning ratios are similar to the average of $8.8 \pm 6.0$ (range 4.3 to 25 ) for residential burning, calculated from the values summarized by Szidat et al. (2006) for a literature survey of 11 studies. Recent investigations (N. Perron, personal communication, 2009) have shown that the fossil/non-fossil separation is more uncertain for EC than for OC. Different OC/EC separation methods may lead to differences in the fossil/non-fossil contributions in the EC fraction.

\section{Results}

\subsection{Analysis of BB impacts using satellite fire counts and FLEXPART modeling}

\subsubsection{Observed correlation between satellite fire data and AMS BBOA}

Total fire counts from MODIS summed within several concentric circles centered on $\mathrm{T} 0$ and of increasing radii are shown in Figs. 1 and S1 (http://www.atmos-chem-phys. net/10/5315/2010/acp-10-5315-2010-supplement.pdf). The fires for the area near Mexico City (circles of radii 60 and $120 \mathrm{~km}$ centered in T0) were more intense during MILAGRO than the recent climatological average for the same period, with approximately twice as many fire counts as compared to the average of recent years. There is high variability in the fire counts, consistent with the high variability in the BBOA impacts observed in the PMF-AMS and CMB-OMM results from T0 reported previously (Stone et al., 2008; Aiken et
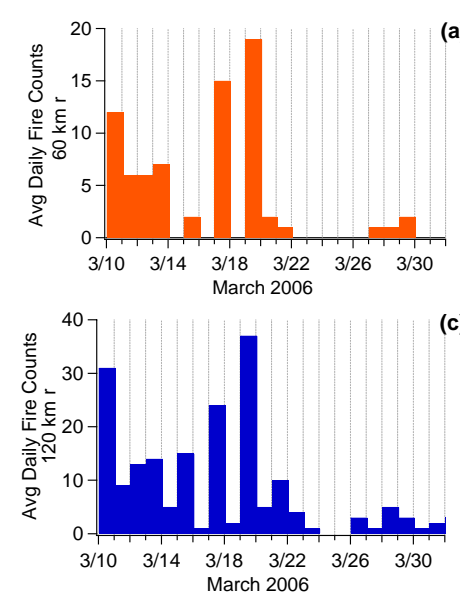

(c)
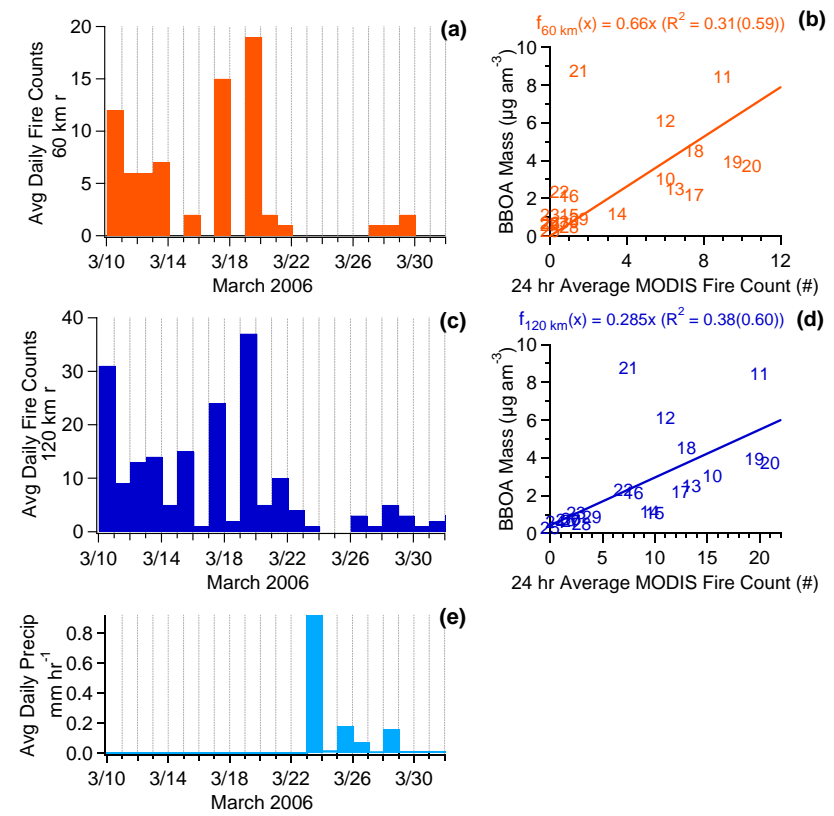

(e)

Fig. 1. MODIS fire counts over 24-h intervals for circles centered at T0 with two different radii, $60 \mathrm{~km}$ and $120 \mathrm{~km}$, (a, c) during the sampling period and $(\mathbf{b}, \mathbf{d})$ plotted against the daily BBOA mass average. In (b and d), datapoint symbols indicate the day of the month in March, and the average of the fire counts is a 24-h average from that day plus the previous day counts. Daily average precipitation plotted over 24-h intervals (e). Here and in all subsequent figures, the longer tick marks on the $\mathrm{X}$-axis and a date label correspond to midnight local time.

al., 2009) and for acetonitrile and levoglucosan at T1 (de Gouw et al., 2009). There is a clear decrease in the number of fires after 22 March due to higher precipitation and humidity (Fig. 1e; Fast et al., 2007). For the larger circles, $\geq 250 \mathrm{~km}$ radii, increased fire counts are observed during the month of April in comparison to March, consistent with typical dry season patterns for the larger region (Yokelson et al., 2007).

Figure 1 also shows scatter plots of the daily average PMFAMS BBOA concentration vs. the daily fire counts (averaged for the same and previous day to approximately account for transport time). The AMS BBOA shows a positive correlation with the fire counts for both scales $\left(R^{2} \sim 0.31-0.38\right)$, which suggests that this component is influenced by emissions from fires located in the mountains near Mexico City. If the day with the largest observed BBOA plume, 21 March, is removed from the correlation analysis, $R^{2}$ increases to $0.58-$ 0.62 . The fact that BBOA is highest on that day despite lower fire counts is believed to be due to a "direct hit" of T0 by a plume from one nearby fire (see below), which results in a BBOA concentration higher than expected from the overall fire counts. 
(a)

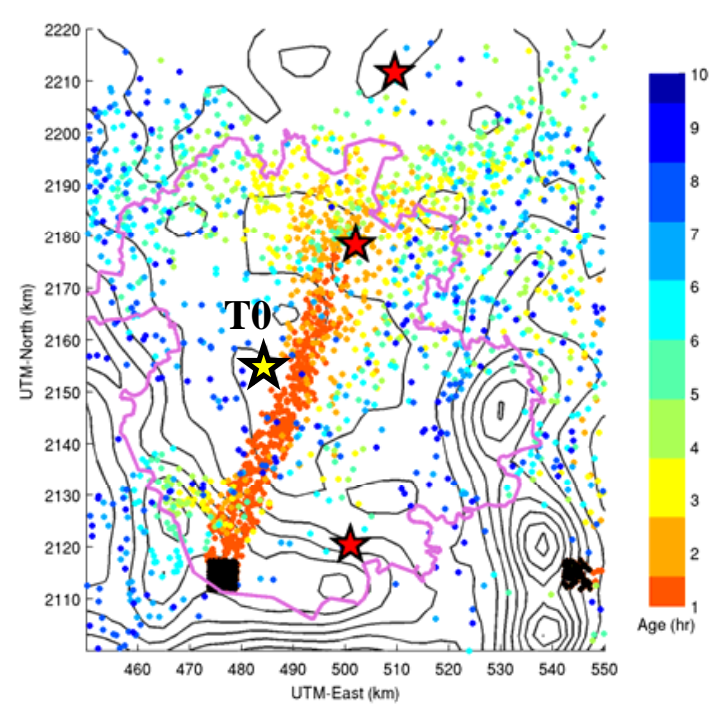

(b)

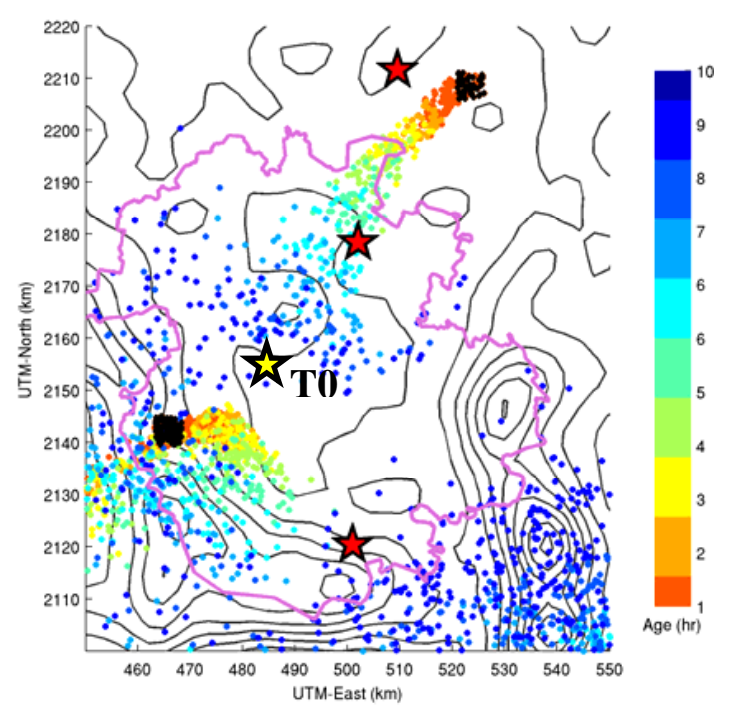

Fig. 2. Modeled fire impact over MCMA with FLEXPART forward trajectories during (a) the evening of 20 March (18:00-19:00 CST) and (b) the early morning of 21 March (04:00-05:00 CST). Stars represent Santa Ana, T0, T1, T2, from South to North, with T0 in yellow. Black squares represent the fires.

Previous studies have estimated that the BBOA impacting Mexico City during MILAGRO was dominated by the emissions from fires in the nearby mountains (Yokelson et al., 2007). Although the correlation coefficient with fire counts increases slightly for larger circles around T0 $\left(R^{2} \leq 0.45\right.$; Fig. S2a-d http://www.atmos-chem-phys.net/10/5315/2010/ acp-10-5315-2010-supplement.pdf), this is most likely due to the reduced impact of statistical noise in the larger number of fire counts on the larger circles, and not due to an impact of distant fires as discussed below. The dominant association of BBOA with nearby fires is in contrast with the larger impact of fires from the Yucatan peninsula during the later part of April 2003 in the MCMA-2003 field campaign (Salcedo et al., 2006; Molina et al., 2010) when the Yucatan fire counts were more than an order-of-magnitude higher than during MILAGRO and the meteorological conditions favored transport towards Mexico City.

No positive correlation was apparent between the fire counts and any OA component other than BBOA (Fig. S3 http://www.atmos-chem-phys.net/10/5315/2010/ acp-10-5315-2010-supplement.pdf). In particular there is a negative, rather than positive, correlation for OOA suggesting that the contribution of the fires near Mexico City to OOA at T0 is small. One exception occurs during 20-22 March when smoke from fires lingered in the Mexico City region and substantial formation of OOA from BB emissions was likely, as indicated by elevated molecular tracer measurements (Stone et al., 2008; Aiken et al., 2009). There is also little correlation $\left(R^{2}<0.08\right)$, between the daily averages of
BBOA and HOA or OOA, indicating that the BBOA component resolved by PMF is likely capturing the bulk of the OA from the regional fires that reached T0 during this study.

It is also of interest to investigate whether the regional fires make a larger contribution to the regional background $\mathrm{OA}$, since they are more diffuse than the urban emissions (DeCarlo et al., 2008; Crounse et al., 2009). Regional background aerosol has been observed by many studies to have a spectrum similar to that of OOA (e.g. Alfarra et al., 2004; Zhang et al., 2005b, 2007), and SOA formed from BB also has a spectrum similar to ambient OOA (Grieshop et al., 2009; Jimenez et al., 2009). Thus, we examined whether the OOA background had an increase during the periods with higher fire counts near Mexico City. Since there is substantial ventilation of the basin during the afternoon (de Foy et al., 2009), the best estimate of the more regionally-influenced OOA background from the T0 data is the OOA concentration during the late night/early morning periods, which consistently have the lowest observed concentrations of OOA over the diurnal cycle (Aiken et al., 2009). The OOA background (defined as the average from 8 p.m.4 a.m.) has no clear trend of increase during times with increased regional fire counts $\left(R_{60} \mathrm{~km}=-0.05 ; R_{120} \mathrm{~km}=\right.$ 0.00; Fig. S3c http://www.atmos-chem-phys.net/10/5315/ 2010/acp-10-5315-2010-supplement.pdf), with 21 March being an exceptional day that does appear to show an increase in the OOA background due to BB SOA. 


\subsubsection{FLEXPART modeling of fire impact factors at T0 and comparison to observations}

Because the fire count data does not account for meteorological transport and dispersion, FLEXPART particle trajectories were calculated for tracers of $\mathrm{CO}$ emissions as described in Sect. 2.2. Figure 2 shows two examples of the model results from 20 and 21 March when intense BBOA plumes, $>15 \mu \mathrm{g} \mathrm{am}^{-3}$, were detected (marked in Fig. 3 as F20 and F21). FLEXPART indicates fire plumes affecting T0 from the south-south-west of T0 on March 20 (Fig. 2a), and the north east on 21 March (Fig. 2b). Simulated fire trajectories show an impact at T0 between 6 and 7 p.m. on 20 March, which corresponds to an increase in BBOA from 5 to 8 p.m. This indicates a high probability that the BBOA measurements are due to the wildfire detected by MODIS. Discrepancies between BBOA concentration events and simulated FIFs are particularly sensitive to the timing of emissions. At present, satellite observations from the overall GOES diurnal profile are used here as a first-order approximation that does not take into account the timing of individual fires and the length of smoldering emissions.

Two FIFs were obtained by counting FLEXPART particles within a 9 by $9 \mathrm{~km}$ grid box centered on T0 extending from the surface to $2000 \mathrm{~m}$ above ground. The first FIF assumes fire emissions from 12:00 to 20:00, consistent with the diurnal profile of all potential fires detected by GOES in the basin. The second FIF assumes emissions from 14:00 to 24:00, with the later start taking into consideration only fires with higher levels of GOES quality assurance, and the later end extending the emission period to account for additional smoldering emissions. FIFs calculated over a $40 \mathrm{~km}$ by $40 \mathrm{~km}$ square centered on the city look like a smoothed version of the FIFs at T0 discussed here (shown in Fig. S4 http://www.atmos-chem-phys.net/10/5315/2010/ acp-10-5315-2010-supplement.pdf).

The time series of predicted FIFs are plotted together with the time series of BBOA and fire counts, and also as scatter plots in Fig. 3. Most of the BBOA dynamics and intense plumes are captured by the FIFs, yet the relative intensity is not always predicted accurately. The two different FIFs show some differences, most notably FIF $_{14-24}$ captures the BBOA peak on the morning of the 18th while FIF $_{12-20}$ does not, indicating that this BBOA plume is likely due to the transport of $\mathrm{BB}$ emissions from a nighttime smoldering fire. During the complete time series, FIF $_{14-24}$ better captures the variability of BBOA $\left(R^{2}=0.62\right.$, vs. 0.26 for $\left.\mathrm{FIF}_{12-20}\right)$.

There are also a few small peaks in BBOA on the 16th that neither FIF predicts, and a few predicted impacts that are not seen in the BBOA. Overall, the prediction of the trends of the fire impact (especially by $\mathrm{FIF}_{14-24}$ ) appears quite successful, and the differences in the observed ratios of impact/BBOA from day-to-day are not unexpected given the uncertainties in the satellite fire counts, amounts of fuel burned per fire count, the emission factors of $\mathrm{CO}$ per unit fuel burned, and the fact that the modeled emissions are proportional to $\mathrm{CO}$ while the BBOA/CO ratio is very likely to vary across different fires (see below; Reid et al., 2005). The agreement also suggests that the larger fires that are detectable with satellites dominate the total $\mathrm{BB}$ emissions. The diurnal cycles of both FIF are shown in Fig. 3f, suggesting that impacts should be highest at night and lowest in the mid-morning and early afternoon, again consistent with the AMS BBOA and acetonitrile observations (Aiken et al., 2009). BBOA and acetonitrile peak even later in the early morning (Aiken et al., 2009), which suggests that smoldering emissions may be active past 24:00 of the day in which the fire count was detected. Figure S5 (http://www.atmos-chem-phys.net/10/ 5315/2010/acp-10-5315-2010-supplement.pdf) shows scatter plots of all OA components and of total OA vs. FIF $_{14-24}$, again with much lower correlation for other components than that found for BBOA.

FIF $_{14-24}$ is broken down depending on the distance of the emission point from T0 in Fig. 4. The dominant impact $(63 \%)$ is from the fires within a $60 \mathrm{~km}$ circle of Mexico City, followed by those between $60-120 \mathrm{~km}(13 \%)$. The predicted impact from fires farther away (18\% for $120-1000 \mathrm{~km})$ and from fires in the Yucatan $(5 \%)$ is small during this period. Given the good correlation between the total predicted fire impact factors and BBOA (and other fire tracers, see below), this analysis strongly suggests that the main source of BBOA at T0 during MILAGRO were emissions from open BB near the MCMA.

\subsection{Alternative analyses using different tracers for BB emissions}

\subsubsection{Intercomparison of different BB tracers}

A number of different tracers of BB have been used in the literature, including multiple MILAGRO studies. For example, Stone et al. (2008) use levoglucosan, de Gouw et al. (2009) use levoglucosan and acetonitrile, Crounse et al. (2009) use $\mathrm{HCN}$ and acetonitrile, Yokelson et al. (2007) use HCN, DeCarlo et al. (2008) use HCN and AMS $m / z$ 60/OA, Aiken et al. (2009) use levoglucosan, acetonitrile, and AMS levoglucosan-equivalent mass (levog.-eq. mass, which includes other fire tracer species such as mannosan and galactosan), and Moffet et al. (2008a) and Gilardoni et al. (2009) use potassium $(\mathrm{K})$.

Given the variations in the conclusions concerning the relative impacts and diurnal cycles of BB during MILAGRO, it is of great interest to intercompare the different tracers and evaluate whether a lack of correlation could imply the influence of different types of fires, or influences of other non-BB sources for some tracers, or degradation for some of the tracers. Large differences in some BB tracer emissions are sometimes observed in microscale emissions such as emissions from burning small amounts (e.g. $200 \mathrm{~g}$ ) of individual plant species, and also due to different emission rates in flaming 

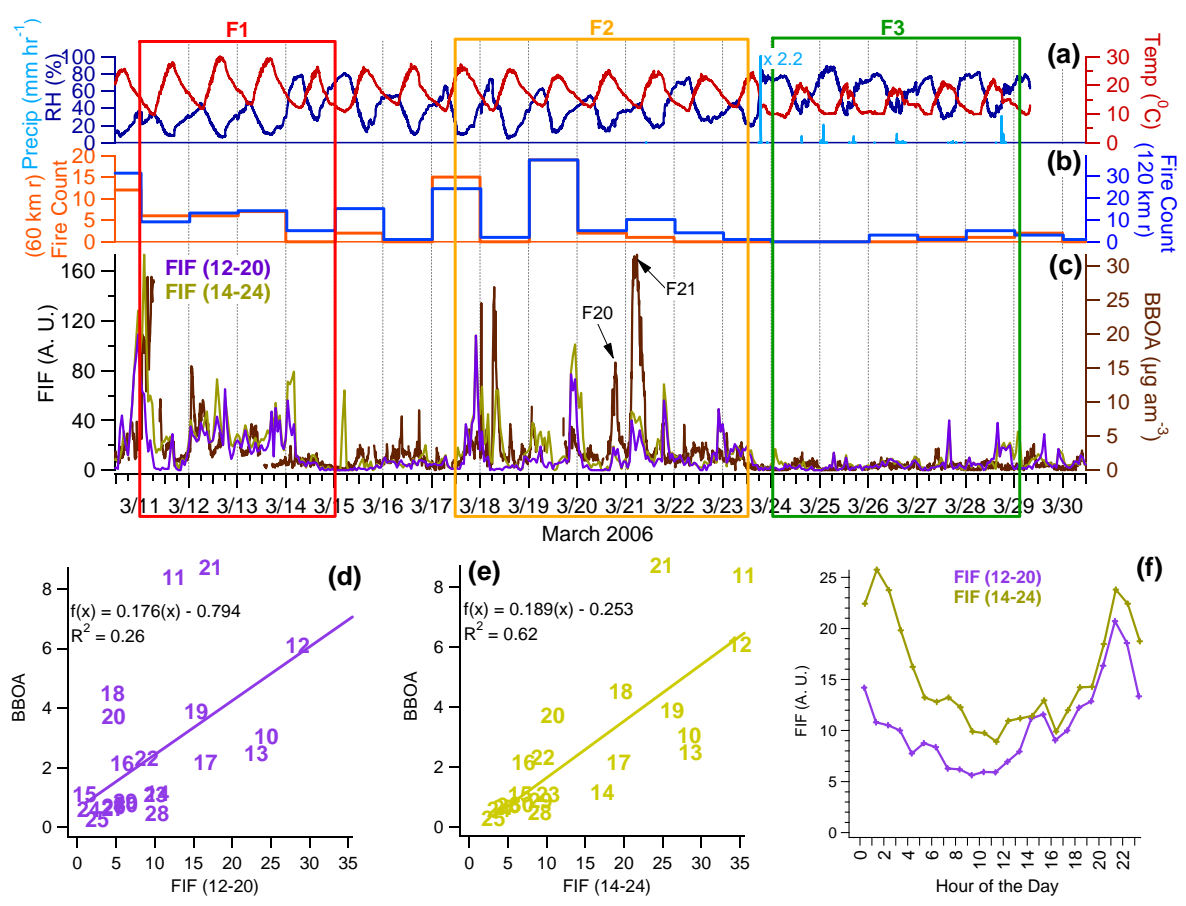

Fig. 3. Time series of (a) ambient temperature and humidity at T0; (b) MODIS fire counts within circles centered in T0 of 60 and $120 \mathrm{~km}$ radii; (c) FLEXPART Fire Impact Factors (FIF) and AMS BBOA, with fire impact periods (F1, F2, F3) labeled. (d, e) Scatter plot of BBOA at T0 vs. the two FIF, datapoint symbols are the day of March 2006; (f) Diurnal cycle of the two FIF at T0.

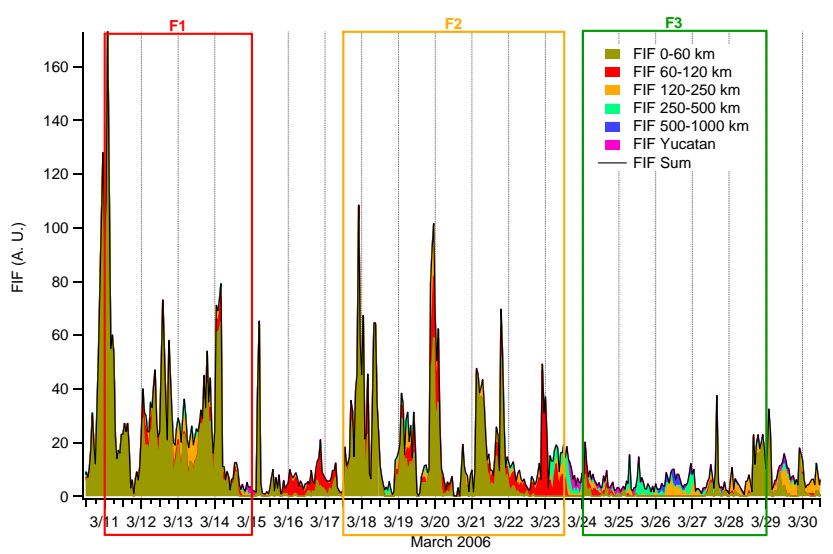

Fig. 4. Time series of the $\mathrm{FIF}_{14-24}$ broken down according to the distance from $\mathrm{T} 0$ at which the fire emissions took place. Fire impact periods are also marked.

vs. smoldering combustion (Sullivan et al., 2008). However, previous literature studies suggest that when integrated at the field scale the different tracers are generally well-correlated in different open BB sources (Andreae and Merlet 2001) and biofuel combustion sources (Sheesley et al., 2003), as well as in ambient measurements influenced by open burning (Graham et al., 2002; Hudson et al., 2004; Saarikoski et al., 2007) and residential burning (Caseiro et al., 2009).
In the companion paper (Aiken et al., 2009) it was shown that AMS levog.-eq. mass and GC-MS levoglucosan were well-correlated $\left(R^{2}=0.73\right.$, see Fig. 5e in that paper). Figures 5a-b show scatter plots of daily average $\mathrm{CH}_{3} \mathrm{CN}$ vs. AMS levog.-eq. mass and GC-MS levoglucosan. In these and subsequent plots we use daily averages (on the appropriate time grids) due to the availability of the levoglucosan data only as daily averages, and the high level of noise in several of the tracers. Scatter plots and regressions using higher time resolution data show similar patterns with more scatter (not shown).

$\mathrm{CH}_{3} \mathrm{CN}$ is correlated with both tracers $\left(R^{2}=0.43\right.$ with levog.-eq. mass and 0.56 with levoglucosan). The $\mathrm{CH}_{3} \mathrm{CN}$ background when the other tracers are zero (positive Yintercept) is similar to the tropospheric background of 100 $150 \mathrm{pptv}$ within the regression uncertainties. These results suggest that $\mathrm{CH}_{3} \mathrm{CN}$, AMS levog.-eq. mass, and GC-MS levoglucosan contain similar information about BB impacts on the average, with some day-to-day variability arising from either noise in the measurements or variability in the emission ratios and aging. Fig. 5c shows a scatter plot of AMS levog.eq. mass vs. the AMS BBOA identified with PMF. The two tracers show high correlation $\left(R^{2}=0.95\right)$ but are not identical, due to the influence of ions other than $\mathrm{m} / \mathrm{z} 60$ in the AMS BBOA determination by PMF and the subtraction of a fraction of the $m / z 60$ signal due to SOA as discussed previously (Aiken et al., 2009). 

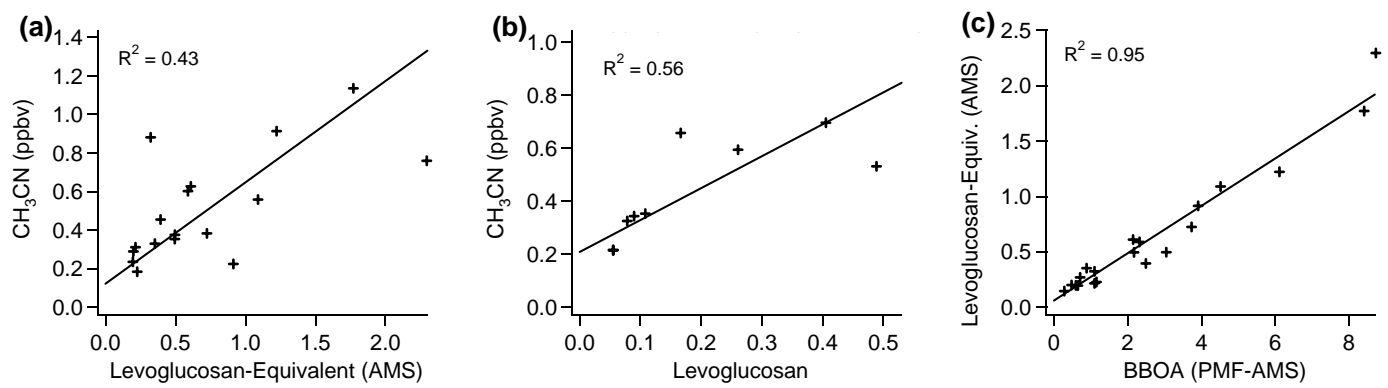

Fig. 5. (a, b) Gas-phase CH3CN (acetonitrile) vs. AMS levoglucosan-equivalent mass (Aiken et al., 2009), GC-MS levoglucosan (Stone et al., 2008). (c) Scatter plot of levoglucosan-equivalent mass vs. AMS BBOA.
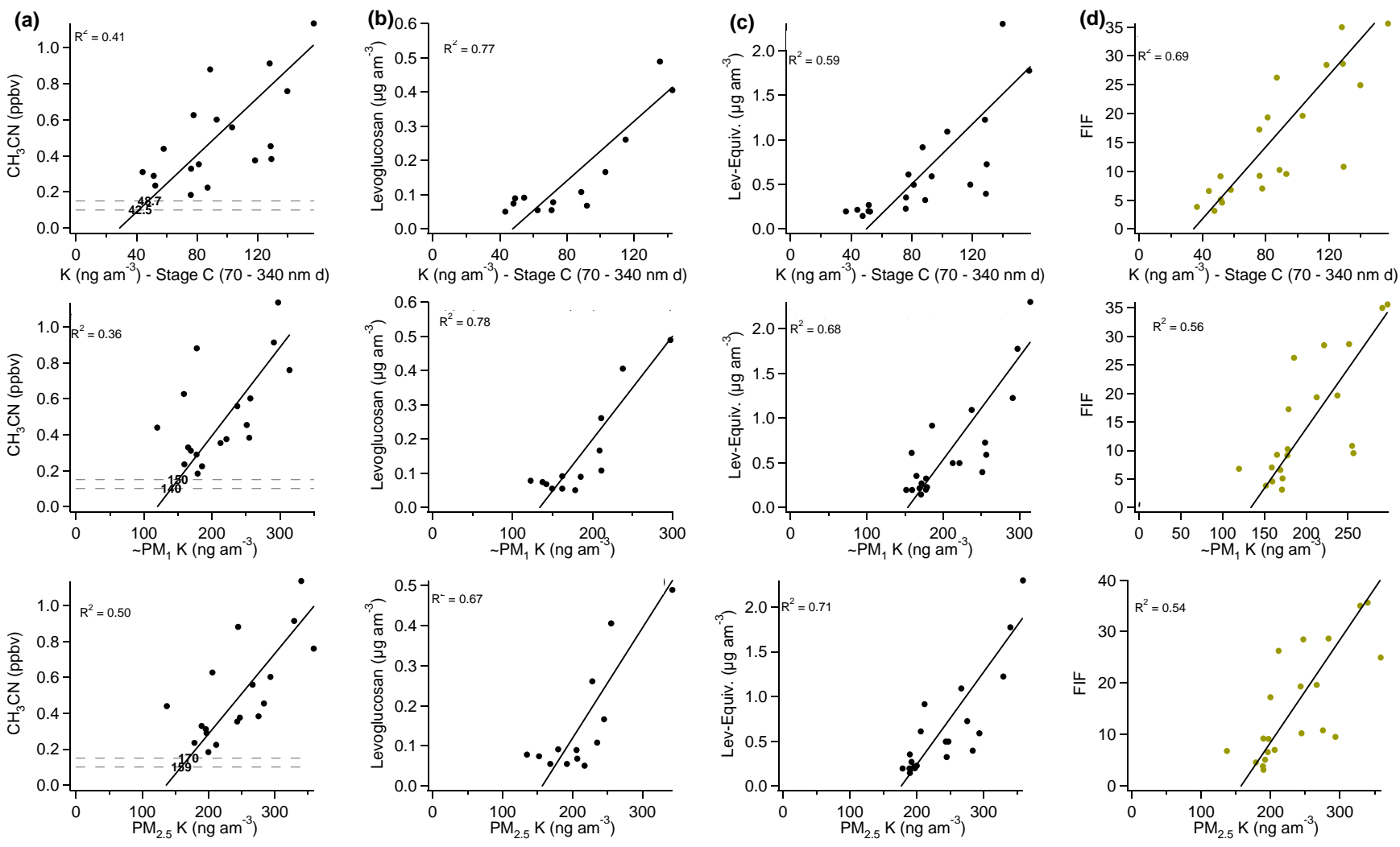

Fig. 6. (a) Acetonitrile (PTR-MS); (b) Levoglucosan (GC-MS); (c) Levog.-eq. mass (AMS); (d) FIF $14-24$ versus PIXE total Potassium plotted as daily time averages. Each scatter plot is shown for the smallest PIXE size bin (70-340 nm), and for approx. $\mathrm{PM}_{1}$, and $\mathrm{PM}_{2.5}$. Lines are two-sided robust linear fits.

Figure 6 presents scatter plots of $\mathrm{CH}_{3} \mathrm{CN}$, levoglucosan, levog.-eq. mass, and $\mathrm{FIF}_{14-24}$ vs. three size fractions of the PIXE K concentrations $\left(\mathrm{PM}_{0.34}, \mathrm{PM}_{1}\right.$, and $\left.\mathrm{PM}_{2.5}\right)$. The different tracers are always correlated to the $\mathrm{K}$ fractions although with substantial scatter in some cases $\left(R^{2}=0.36-\right.$ 0.78). In particular the correlation of the $\mathrm{K}$ fractions with FIF $_{14-24}$ (Fig. 6d) strongly implies that the main source of variability of the fine $\mathrm{K}$ concentrations are the fires near Mexico City described above. The regressions of all parameters against $\mathrm{K}$ show a consistent background level of $\mathrm{K}$ (positive $\mathrm{X}$-intercept) when other parameters are zero (for lev- oglucosan, levog.-eq. mass, and $\left.\mathrm{FIF}_{14-24}\right)$ or are at the tropospheric background level (for $\mathrm{CH}_{3} \mathrm{CN}$ ). The background level of $\mathrm{K}$ is of the order of $45 \mathrm{ng} \mathrm{am}^{-3}, 140 \mathrm{ng} \mathrm{am}^{-3}$, and $160 \mathrm{ng} \mathrm{am}^{-3}$ for the $\mathrm{PM}_{0.34}, \mathrm{PM}_{1}$, and $\mathrm{PM}_{2.5}$ fractions, respectively, which correspond to $\sim 1 / 2$ of the average $\mathrm{K}$ in $\mathrm{PM}_{0.34}$, and about $\sim 2 / 3$ of the average $\mathrm{K}$ in $\mathrm{PM}_{1}$ and $\mathrm{PM}_{2.5}$.

Similar K backgrounds and correlations with wildfire impacts were observed during MCMA-2003 (Johnson et al., 2006). Thus there is a very substantial background concentration of $\mathrm{K}$ at $\mathrm{T} 0$ when all other fire tracers reach background levels. Studies using total $\mathrm{K}$ as a tracer for BB during 


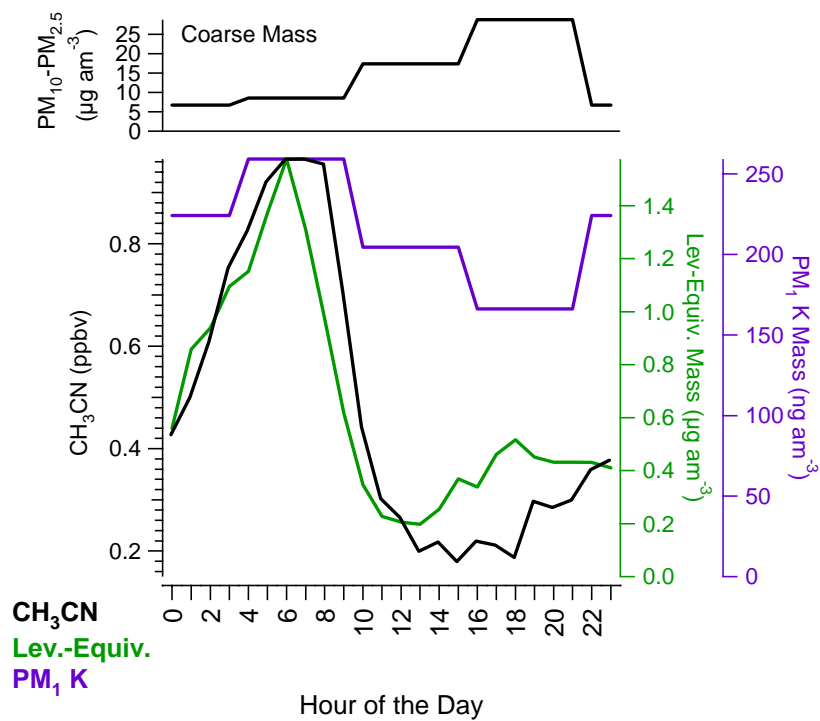

Fig. 7. Top: Diurnal cycle of coarse $\mathrm{PM}\left(\mathrm{PM}_{10}-\mathrm{PM}_{2.5}\right)$ from the measurements of Querol et al. (2008). Bottom: Diurnal cycles of gas-phase acetonitrile, AMS levoglucosan-equivalent mass, and $\mathrm{PM}_{1}$ total potassium.

MILAGRO may thus overestimate the BB contribution by a factor of 2-3. Similarly, the diurnal cycle of $\mathrm{K}$ shows its highest values in the early morning at the same time at which acetonitrile and levog.-eq. mass peak (Fig. 7) and consistent with the diurnal cycle of the FIF from FLEXPART. However $\mathrm{K}$ does not reach as low of a valley in the afternoon as the other tracers, potentially due to the influence of dust $\mathrm{K}$ as discussed below. This trend is especially apparent in the low fire period defined below (Fig. S6 http://www.atmos-chem-phys. net/10/5315/2010/acp-10-5315-2010-supplement.pdf), consistent with the dominance of non-fire sources to the afternoon $\mathrm{K}$ background.

Note that while the diurnal profile of acetonitrile is similar to that measured at T1 by de Gouw et al. (2009), its diurnal amplitude is about $2 \times$ larger. The diurnal amplitude of other pollutants such as $\mathrm{CO}$ is also much larger at $\mathrm{T} 0$ than at $\mathrm{T} 1$, due to the stronger influence of urban emissions at the former site, and urban emissions may also explain the higher diurnal amplitude of acetonitrile at T0. An alternative explanation for this observation is the closer location of $\mathrm{T} 0$ to the mountains and thus the forest fires. Given the incomplete understanding of the acetonitrile sources at $\mathrm{T} 0$, we cannot reach a more definitive conclusion based on the data and analysis in this paper.

In principle there are at least three possible explanations for the high fine $\mathrm{K}$ background. First, there could be a persistent influence of $\mathrm{BB}$ sources that are not related to the fire counts and that emit $\mathrm{K}$ but do not emit $\mathrm{CH}_{3} \mathrm{CN}$, levoglucosan, and levog.-eq. mass. Due to the persistence of the $\mathrm{K}$ background at all times including when fire counts are zero, this would need to arise from an urban source. How- ever this appears unlikely given the co-emission of $\mathrm{K}$ and the other tracers which has been reported in previous BB studies including those mainly influenced by woodstove or biofuel combustion (e.g. Andreae and Merlet 2001; Caseiro et al., 2009, see discussion above). Although levoglucosan can be photochemically degraded in the atmosphere, elevated levels of levog.-eq. mass have been observed in multiple fire plumes intercepted by aircraft thousands of $\mathrm{km}$ from their sources (Cubison et al., 2008). Similarly although some degradation of levoglucosan is observed in chamber oxidation experiments of biomass burning particles, a substantial fraction of the levoglucosan does not react away (Hennigan et al., 2010). Thus complete degradation would be very unlikely within the transport scales of this study $(50-100 \mathrm{~km})$, especially since the smoke transport that impacts T0 most strongly happens at night as discussed above. Acetonitrile has a lifetime of several months in the troposphere and should not decay significantly in the time scales of this study. Thus we conclude that the probability of the background $\mathrm{K}$ to arise from $\mathrm{BB}$ sources of any type is very low.

Second, $\mathrm{K}$ is a major component of some types of dust such as illite that likely contribute to the $\mathrm{K}$ concentration in Mexico City (Querol et al., 2008), The diurnal cycle of coarse PM ( $\left.\mathrm{PM}_{10}-\mathrm{PM}_{2.5}\right)$, used here as a surrogate for dust (Querol et al., 2008) is also shown in Fig. 7a. The total K diurnal cycle could be approximately reconstructed as a contribution from BB with a diurnal cycle similar to that of acetonitrile and levog.-eq. mass, and a contribution from dust with the diurnal cycle of the coarse PM, supporting this possibility.

Finally, a third possibility is that there are other urban sources of $\mathrm{K}$ which are not related to either BB or dust. In particular meat cooking has been identified as a significant source of $\mathrm{K}$ in several studies, which warned of the potential confounding of this source with woodsmoke (Hildemann et al., 1991; Schauer et al., 1999). Other non-BB sources with known emissions of $\mathrm{K}$ include vegetative detritus (Hildemann et al., 1991), fly ash (Lee and Pacyna 1999), and some types of vehicles according to one study (Hildemann et al., 1991). In addition, only water-soluble $\mathrm{K}$ is thought to arise from BB sources (Lee et al., 2005) but for MILAGRO the available measurements are only of total K. Future studies should include a separate determination of water-soluble K.

The specific sources responsible for the $\mathrm{K}$ background in Mexico City should be the target of future studies, but for the purposes of the analysis of the BB contribution during MILAGRO, it is critical to account for the fact that $1 / 2$ to $2 / 3$ of the fine total $\mathrm{K}$ mass is most likely not related to BB sources. Thus, although $\mathrm{K}$ is considered as a reliable $\mathrm{BB}$ tracer in the free-troposphere (Hudson et al., 2004), one should be careful about interpreting total potassium $(\mathrm{K})$ as a tracer arising only from BB sources at very complex surface locations impacted by other K sources such as the MCMA. E.g. if the estimate of $1 / 2$ to $2 / 3$ of the fine $K$ from non-BB sources is applied to the estimate of $40 \%$ of K-containing particles from Moffet 
et al. (2008a), the conclusion is that $13-20 \%$ of the particle number is due to $\mathrm{BB}$ sources at $\mathrm{T} 0$, which is much more consistent with all of the other BB estimates presented in this paper. Similarly Gilardoni et al., estimated that about 1/6th of the $\mathrm{K}$ on average was due to non-BB sources (from their Fig. 6c). If we use the estimate of non-BB $\mathrm{K}$ derived here instead, their range estimate of the upper limit contribution of BB to OC goes from 33-39\% to 13-23\% at the SIMAT site, again much more consistent with the estimates based on other techniques.

\subsubsection{Evaluation of the correlation between fire tracers and AMS OA components}

Section 3.1.1 (Fig. S3 http://www.atmos-chem-phys.net/ 10/5315/2010/acp-10-5315-2010-supplement.pdf) reported the lack of correlation between any PMF-AMS OA components (other than BBOA) and fire counts. Here we revisit this question by analyzing the correlation between the PMF-AMS OA components and FIF $14-24$ (Fig. S5 http://www.atmos-chem-phys.net/10/ 5315/2010/acp-10-5315-2010-supplement.pdf) and $\mathrm{PM}_{1} \mathrm{~K}$ (Fig. S7 http://www.atmos-chem-phys.net/10/5315/2010/ acp-10-5315-2010-supplement.pdf). As was the case for the fire counts, a clear correlation is observed between the AMS BBOA and both parameters $\left(R^{2}=0.62\right.$ and 0.73 , respectively) while much lower correlations are observed for other components or total OA. In particular, no correlation is observed for HOA or LOA, and a weak negative correlation is observed for OOA. Thus this evaluation reinforces the conclusion that BBOA is dominated by the impact of open $\mathrm{BB}$ sources at $\mathrm{T} 0$, and that the other $\mathrm{OA}$ components are dominated by other sources.

\subsection{Analysis of open BB contribution to different species by comparing different fire impact periods}

In this section, we use the consistent results from fire counts, FLEXPART fire impact modeling, and BB tracers to further analyze the impact of fire emissions to Mexico City pollution during MILAGRO. We first chose three fire impact periods, each of four to six days duration, which are consistent with the three large-scale meteorological regimes described by Fast et al. (2007) and the fire counts, impact modeling, and tracers described above. The first two fire impact periods (F1: 11-15 March, F2: 17.5-23.5 March) both include substantial levels of $\mathrm{BB}$, whereas the third (F3: 24-29 March) comprises the period with lowest BB impact during the study, coincident with the lowest fire counts, and increased precipitation and humidity (Figs. 1, 3 and S5 http://www.atmos-chem-phys.net/10/5315/2010/ acp-10-5315-2010-supplement.pdf) (Fast et al., 2007; de Foy et al., 2008). Stone et al. (2008), whose molecular marker measurements start after the end of period F1, found increased BB impact at T0 on 18, 20-22 March, within F2,
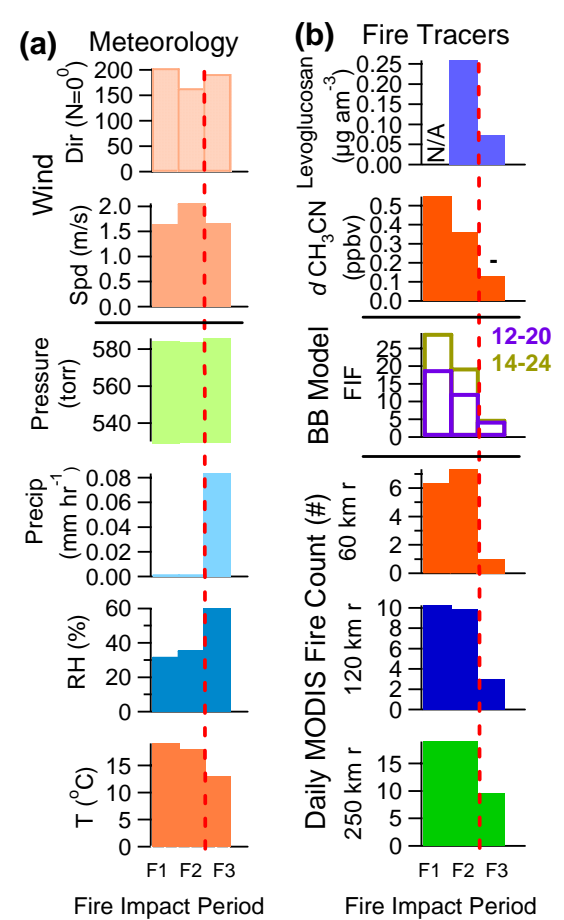

(c) Fire Tracers

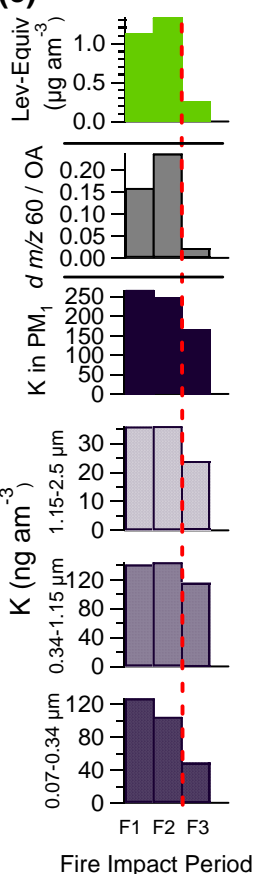

Fig. 8. Fire period analysis graphs, comparing the average values of different parameters for the high fire (F1, F2) and low fire (F3) periods, including (a) meteorology: wind direction, wind speed, ambient pressure, precipitation, $\mathrm{RH}$, and $T$; (b) BB tracers: GC-MS levoglucosan, gas-phase $\Delta \mathrm{CH}_{3} \mathrm{CN}$ above background, fire impact factors $\left(\mathrm{FIF}_{12-20}\right.$ and $\mathrm{FIF}_{14-24}$ ), MODIS fire counts (at 60, 120 and $250 \mathrm{~km}$ radii), (c) additional BB tracers: AMS levoglucosanequivalent mass, AMS $m / z 60 / \mathrm{OA}$, total $\mathrm{K}$ in $\mathrm{PM}_{1}$, total $\mathrm{K}$ in each of the three size bins of the PIXE measurements. (Legend: $-=$ less than $30 \%$ time series, $\mathrm{N} / \mathrm{A}=$ no data).

and much lower impact during F3, which additionally supports these period definitions.

To systematically evaluate the impact of regional fires on different gas and particle-phase species, we average their concentrations during the three periods. We also include averages of some meteorological parameters for reference, and these averages are shown in Figs. 8, 9, 10, and S8. When data for a given variable are not available for at least $1 / 3$ of each fire period, this is denoted with a minus sign in the graph. The F3 period, with low fire counts, is the only one with measurable precipitation, and also has slightly higher RH and lower temperatures. The different fire tracers, counts, and modeled impacts all show a clear contrast between the first two periods F1 and F2, with high fire impact, and F3, with low fire impact (Fig. 8). MODIS fire counts in the two circles closer to the MCMA are 4-6 times larger on average during $\mathrm{F} 1+\mathrm{F} 2$ than $\mathrm{F} 3$, while $\mathrm{FIF}_{14-24}$ is 4.8 times larger when comparing the same periods. AMS levog.-eq. mass shows an enhancement factor of 4.7, consistent with the fire count and $\mathrm{FIF}_{14-24}$ estimates. Excess $\mathrm{CH}_{3} \mathrm{CN}$ (above background) and 

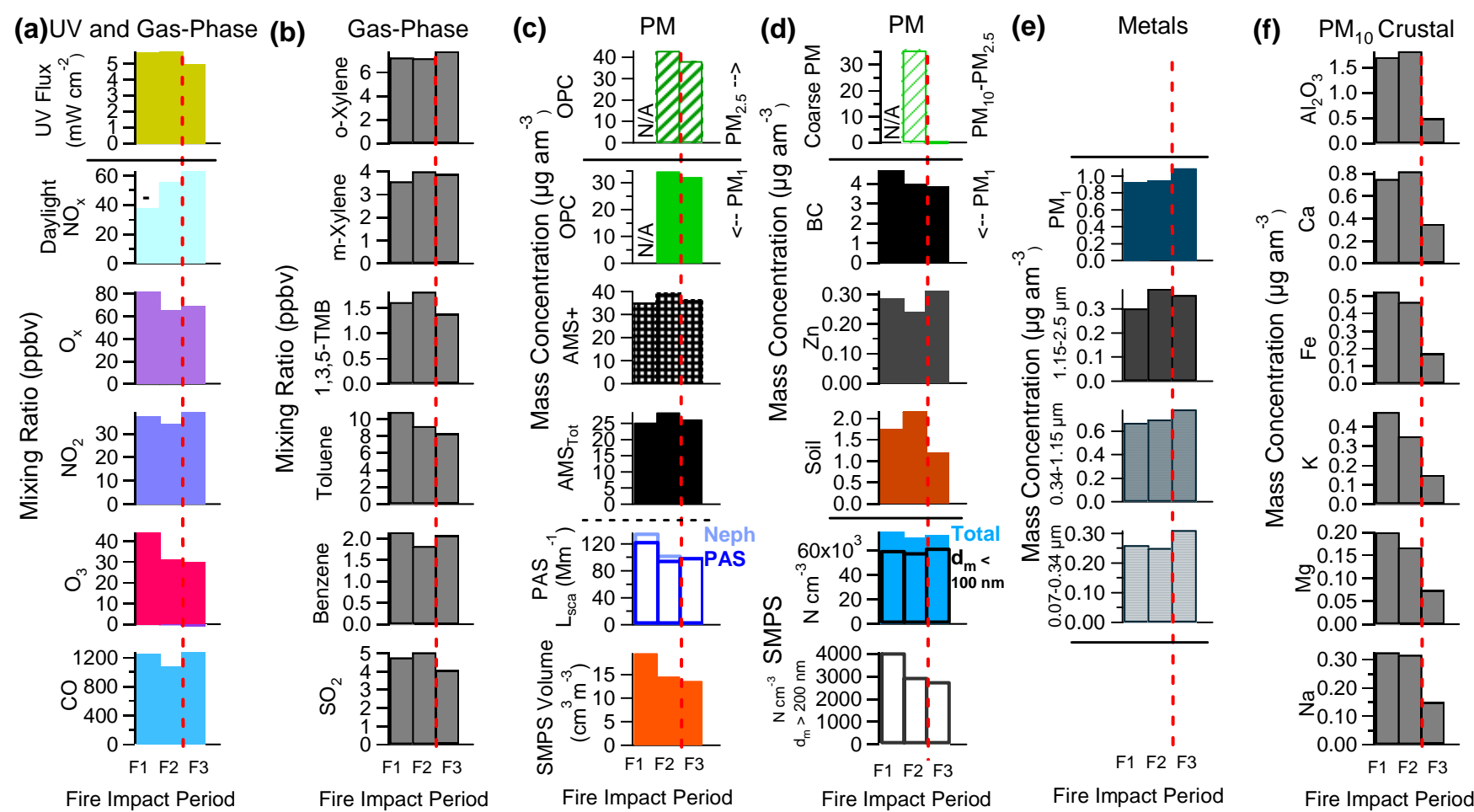

Fig. 9. Fire period analysis graphs, comparing the average values of different parameters for the high fire (F1, F2) and low fire (F3) periods, including (a) UV flux and gas-phase species; (b) aromatic hydrocarbons and $\mathrm{SO}_{2}$; (c) six different measures of fine PM concentration; (d-f) particle-phase species. (Legend: $-=$ less than $30 \%$ time series, N/A=no data).

levoglucosan show enhancements of 3.5 and 3.6 respectively, although in both cases the coverage of the fire periods is not complete. Potassium shows a clearer fire enhancement of 2.4 in the smallest size bin $(0.07-0.34 \mu \mathrm{m})$ and less so at larger sizes (1.6 in $\mathrm{PM}_{1}$ and 1.8 in $\mathrm{PM}_{2.5}$ ), and a large background in low BB periods, indicating the importance of other sources for total $\mathrm{K}$ as discussed above.

In contrast with the fire tracers, $\mathrm{Zn}$ and other metals (Fig. 9d, e), which are not expected to be correlated with fire activity (as they are anthropogenic tracers that have mostly industrial and traffic sources; Moffet et al., 2008b; Moreno et al., 2008; Querol et al., 2008), indeed do not show an enhancement during the high fire periods. Gas-phase CO and aromatic species such as benzene, xylenes, toluene, and 1,3,5-trimethyl benzene (Fig. 9b) also do not show a clear trend when comparing the three periods. This result is consistent with Karl et al. (2009) who estimate that only $\sim 10 \%$ of the benzene measured over the MCMA is due to BB sources, with Crounse et al. (2009) who estimate that $\sim 13 \%$ of the benzene near the surface over Mexico City is due to BB, and with Wöhrnschimmel et al. (2010) who reported only a very minor enhancement of benzene in the MCMA during the $\mathrm{BB}$ season over a multi-year period. The trends for gas-phase $\mathrm{NO}_{2} / \mathrm{NO}_{\mathrm{x}} / \mathrm{O}_{3} / \mathrm{O}_{\mathrm{x}}$ are highly variable, but suggest higher gas-phase photochemical tracers during the first high fire period which is not observed in the second one.
We now focus on several measurements of PM mass (Fig. 9d, e). Coarse PM $\left(\mathrm{PM}_{10}-\mathrm{PM}_{2.5}\right)$ is much higher during the fire periods. Since the coarse fraction is dominated by crustal components (Querol et al., 2008), this difference is most likely due to higher dust emissions during those periods. This is consistent with the variation of several crustal tracers in $\mathrm{PM}_{10}$ (Figs. 9f and S9 http://www.atmos-chem-phys.net/10/5315/ 2010/acp-10-5315-2010-supplement.pdf). It is possible that (a) the main sources of dust are unrelated to the fires and are simply enhanced by the same dry conditions that make fires more likely, or that (b) extra dust is co-emitted by the fires (e.g. dust that has settled on the vegetation and is resuspended due to the turbulence and convection caused by the fire). Figure S10 (http://www.atmos-chem-phys.net/10/ 5315/2010/acp-10-5315-2010-supplement.pdf) shows the time series of BBOA and coarse PM at T0. The lack of detailed correlation in time between the two traces during most periods $\left(R^{2}=0.07\right)$ indicates that most of the coarse PM is not directly related to the fire emissions.

A similar but weaker trend of higher concentration during the high fire periods is observed in the PIXE soil estimate $\left(\mathrm{PM}_{2.5}\right)$ (Fig. 9d), again likely dominated by higher dust emissions during the dry periods. Total $\mathrm{PM}_{2.5}$ shows a small enhancement (13\%) while the $\mathrm{PM}_{2.5}$ total light scattering suggest a larger enhancement (21\%) during the high fire 
(a) AMS (NR-PM $)_{1}$

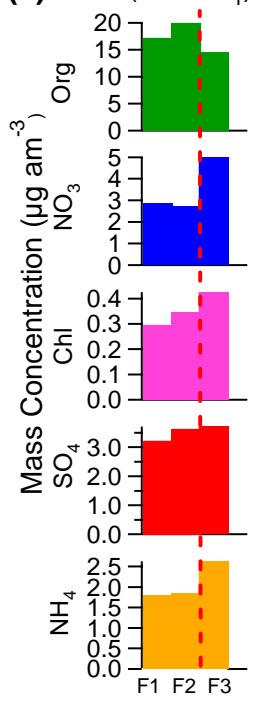

Fire Impact Period

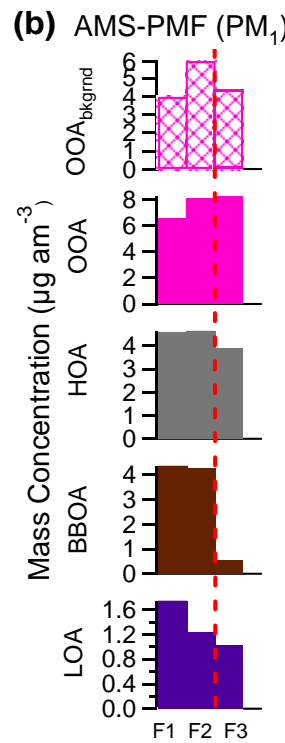

Fire Impact Period

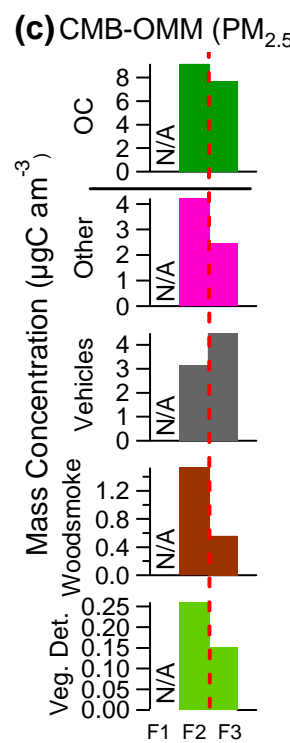

Fire Impact Period

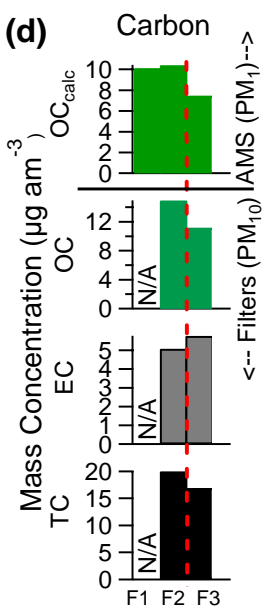

Fire Impact Period

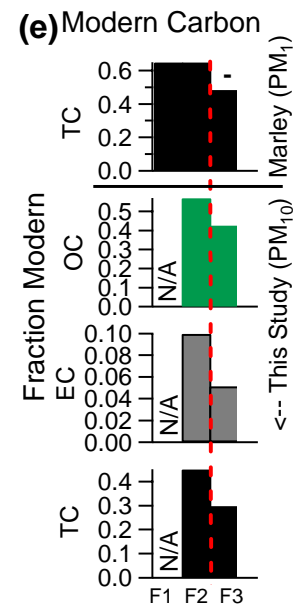

Fire Impact Period

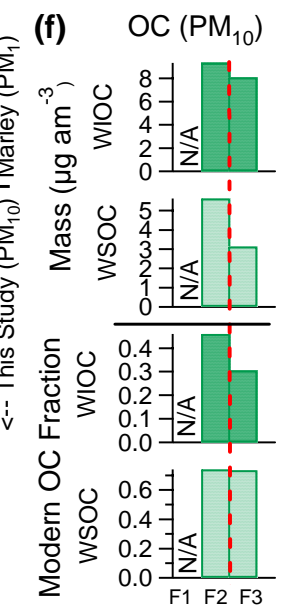

Fire Impact Period

Fig. 10. Fire period analysis graphs, comparing the average values of different parameters for the high fire (F1, F2) and low fire (F3) periods, for (a) AMS species, (b) AMS-PMF factors, (c) CMB-OMM total and factors, (d) carbon mass estimated from the AMS and measured from the ${ }^{14} \mathrm{C}$ filters from this study; (e) fraction of non-fossil carbon for the different datasets, and (f) mass and fraction of non-fossil carbon for the WSOC and WIOC fractions from this study. (Legend: $-=$ less than $30 \%$ time series, N/A=no data).

periods (Fig. 9c), which are likely due to a combination of the fire impacts and the higher dust. Two measures of (approx.) $\mathrm{PM}_{1}$ mass, the sum of speciated measurements and the optical counter measurement, are also shown in Fig. 9c. Taken together these suggest perhaps a small enhancement in total fine $\mathrm{PM}_{1}$ of the order of $5 \%$ during the fire periods (defined as the average of F1 and F2 vs. F3, a calculation used also for all other variables below).

The SMPS apparent volume, which has a lower size cut and is sensitive to the presence of irregular particles, shows more of an enhancement during the fire periods, $25 \%$ on average, which is due to a larger number of particles above $200 \mathrm{~nm} d_{m}$ during $\mathrm{F} 1$ versus the later periods, as the number of particles in the smaller size ranges stays relatively constant.

Next, we discuss the variation of the chemical composition of fine PM species concentrations across the fire periods (Fig. 10a). For the inorganic components, nitrate increases during the low fire period (F3) mainly due to the much reduced uptake by dust with perhaps some influence from favored partitioning at the slightly lower temperature and higher $\mathrm{RH}$ of this period, as discussed in detail in the companion paper (Aiken et al., 2009). Ammonium also shows an increase due to the ammonium nitrate increase, while sulfate shows little change. Non refractory (NR) chloride is higher during the low fire period, which indicates that despite the source of this species during fires (DeCarlo et al., 2008), urban sources and/or favorable partitioning conditions may be more important for this PM species in the MCMA.
BC (Fig. 9d) is slightly elevated $\left(+12 \%, 0.45 \mu \mathrm{gm}^{-3}\right)$ during the high fire periods, consistent with expectations of some emission from fires, e.g. Reid et al. (2005), and previous findings from MCMA-2003 (Molina et al., 2010). Total OA is higher by $+27 \%$ during the fire periods, which is consistent with the BBOA contribution discussed in Part 1 (Aiken et al., 2009). The higher BBOA is responsible for the majority of the OA enhancement: BBOA showed an enhancement of $3.8 \mu \mathrm{g} \mathrm{am}^{-3}$ between F1+F2 $\left(4.3 \mu \mathrm{g} \mathrm{am}^{-3}\right)$ and F3 $\left(0.5 \mu \mathrm{g} \mathrm{am}^{-3}\right)$. This is consistent with the relative enhancements of the fire tracers discussed above. AMS OC (Fig. 10d), calculated using the AMS-measured OA/OC values, is $37 \%$ higher during $\mathrm{F} 1+\mathrm{F} 2$. This is more than the $\mathrm{OA}$ enhancement since BBOA has a lower OA/OC than OOA, the dominant OA component. The enhancement of AMScalculated OC is similar to the increases observed for the different filters.

HOA has a $19 \%$ enhancement during the high fire periods (Fig. 9b), equivalent to $0.75 \mu \mathrm{g} \mathrm{am}^{-3}$, which could be due to several reasons: (a) random variability of the concentration of HOA; (b) higher trash burning emissions during the high fire periods than the wetter F3 period since these open-air burning would also be damped by rain. Christian et al. (2010) report that the large majority of the trash in dumps in the outskirts of Mexico City is plastic, whose burning produces OA emissions with a spectrum very similar to HOA (Mohr et al., 2009); (c) finally a third possibility is that PMF may not be perfectly separating all BBOA from HOA, and that a concentration of the order of $0.75 \mu \mathrm{g} \mathrm{am}^{-3} \mathrm{HOA}$ during the 

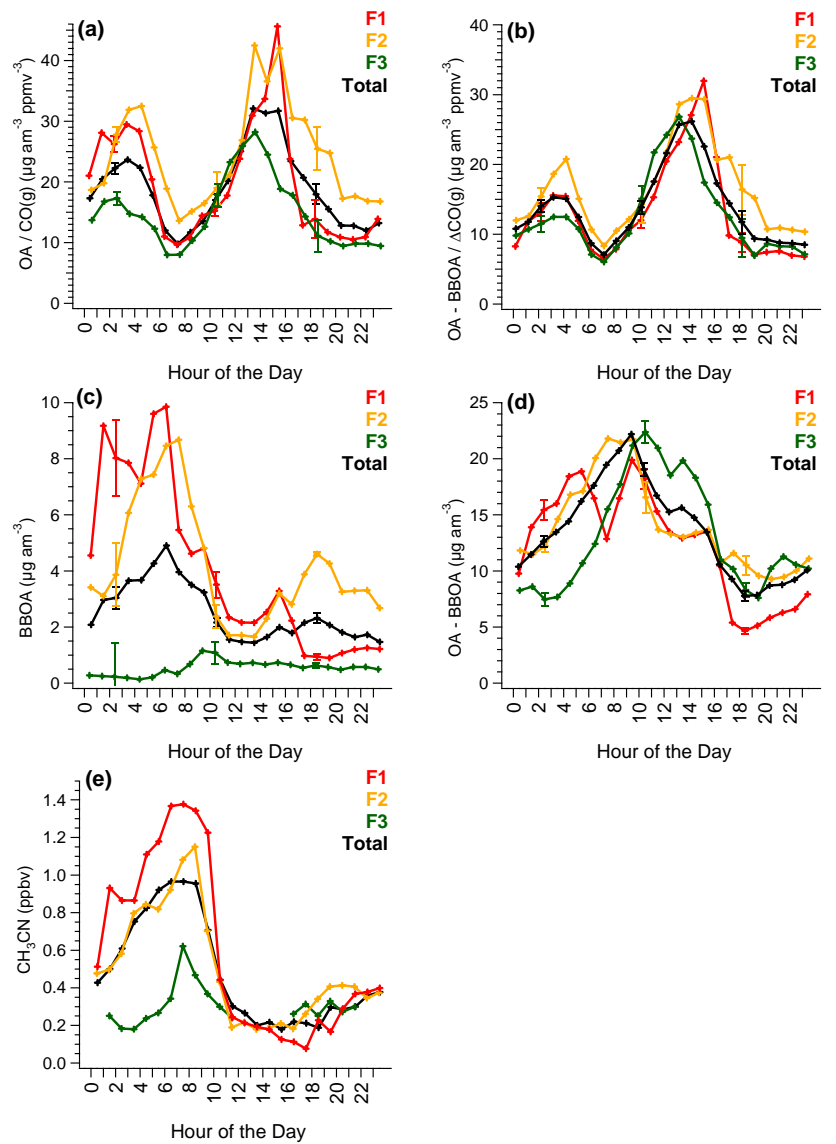

Fig. 11. Diurnal profiles for (a) $\mathrm{OA} / \triangle \mathrm{CO}(\mathrm{g})$, (b) $\mathrm{OA}$ $\mathrm{BBOA} / \triangle \mathrm{CO}(\mathrm{g})$, (c) BBOA, (d) OA-BBOA, and (e) $\mathrm{CH}_{3} \mathrm{CN}$ at $\mathrm{T} 0$ during the whole campaign ("Total") and the three different fire impact periods (high fire: F1, F2; low fire: F3). Error bars are the standard error of the data points for each period, and are shown only at selected points to avoid excessive clutter on the graphs.

high-fire periods may be really of BB origin. The potential effect of the third possibility on the total BB contribution to $\mathrm{OA}$ is discussed below.

The OOA average concentration shows a small change, a $12 \%$ increase during the low-fire period, indicating that the majority of this component arises from sources other than SOA formation from emissions of the wildfires near Mexico City. SOA may also be partitioning slightly more to the particle phase during the slightly colder and more humid period F3, however recent results suggest this effect to be of only a few percent for the conditions of this study (Hennigan et al., 2008; Huffman et al., 2009). The background OOA shows a higher level during F2 (mostly due to the night between 21 and 22 March as discussed above and in Part 1 (Aiken et al., 2009) of $1.76 \mu \mathrm{g} \mathrm{am}^{-3}$ over the other periods. When both fire periods are combined, the background OOA shows an enhancement of $0.57 \mu \mathrm{g} \mathrm{am}^{-3}(11 \%)$. In summary, the combined evidence from the OOA average concentration and the
OOA backgrounds indicates that the SOA produced from $\mathrm{BB}$ sources and that is not already captured in the BBOA factor is not dominating OOA concentrations at T0 during MILAGRO. As discussed above, this may be due to the dispersion of BB smoke in the afternoons (when SOA formation should be more intense) preferentially above the city and often away from it. As discussed above and by Aiken et al. (2009), the largest BBOA and acetonitrile impacts at T0 occur in the early morning and appear to be due to transport of large plumes emitted in the previous late evening and night from smoldering fires, and on which photochemistry has not had time to act.

The LOA component, which is thought to arise from industrial emissions, has an enhancement of $0.47 \mu \mathrm{g} \mathrm{am}^{-3}$ during the high fire periods. This higher concentration is likely due to the variability in this highly irregular and spiky source, including the fact that the low-fire period encompasses the late holiday weekend with lower industrial emissions, rather than to a residual $\mathrm{BB}$ influence as the $R^{2}$ between LOA and $\mathrm{K}$ in $\mathrm{PM}_{2.5}\left(\mathrm{FIF}_{14-24}\right)$ concentrations is $0.00(0.04)$. The changes of the concentration of the various ${ }^{14} \mathrm{C}$ measurements and components are discussed below. To further evaluate the extent to which the PMF-AMS BBOA component captures most of the wildfire emissions, Fig. 11 shows the diurnal profiles of $\mathrm{OA} / \Delta \mathrm{CO}(\mathrm{g}),(\mathrm{OA}-\mathrm{BBOA}) / \Delta \mathrm{CO}(\mathrm{g})$, BBOA, OA-BBOA, and $\mathrm{CH}_{3} \mathrm{CN}$ for the three fire periods. $\mathrm{OA} / \triangle \mathrm{CO}(\mathrm{g})$ is elevated for $\mathrm{F} 1$ and $\mathrm{F} 2$ during the campaign, but most of the difference goes away when OA-BBOA is used, which indicates that the BBOA component is capturing most of the BB influence. The somewhat elevated (OA$\mathrm{BBOA}) / \triangle \mathrm{CO}$ for the late afternoon during $\mathrm{F} 2$ is likely due to the elevated OOA detected in the days after the intense BBOA period on 21 March, as discussed above. The BBOA diurnal profile during the low-fire period $\mathrm{F} 3$ remains below $1 \mu \mathrm{g} \mathrm{am}^{-3}$, while F1 and F2 include profiles that have maximums in the early morning hours approaching 10 and $9 \mu \mathrm{g} \mathrm{am}^{-3}$, respectively. This again suggests that the dominant source of BBOA are fires outside of the city and not urban sources such as biofuel use or food cooking, which would not be expected to show such a large difference between the periods. An upper limit for the potential contribution of OA from open burning sources to other PMF-AMS components can again be derived by the differences between the diurnal profiles in Fig. 11b and d, to be small, of the order of $10 \%$ of the total OA concentration for F1+F2 vs. F3. The $\mathrm{CH}_{3} \mathrm{CN}$ diurnal profiles for the high fire periods are enhanced at night and in the early morning, consistent with the highest $\mathrm{BB}$ impacts at $\mathrm{T} 0$ during this period. During the afternoon and evening the $\mathrm{CH}_{3} \mathrm{CN}$ levels are similar during all fire periods, again supporting the limited BB impact during this part of the day. 


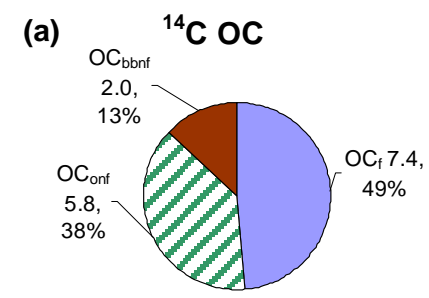

High BB Period

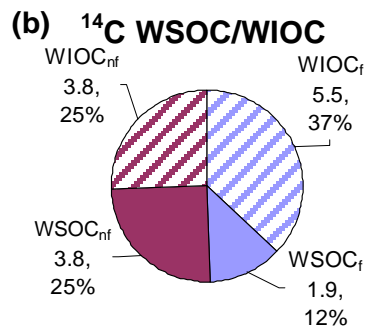

(c)

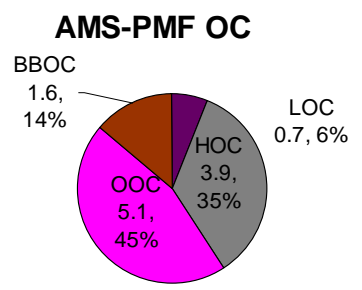

(d)

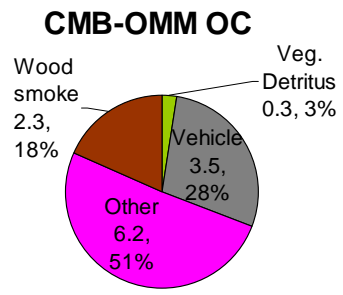

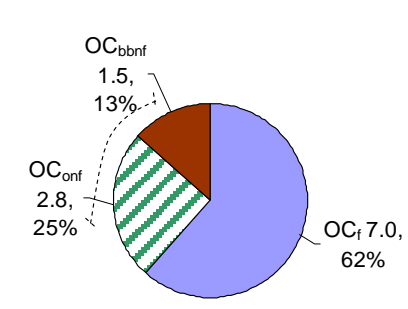

Low BB Period

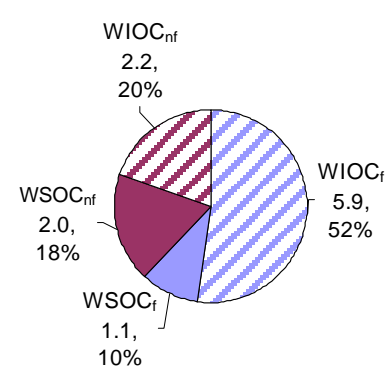

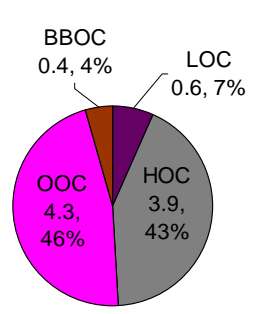

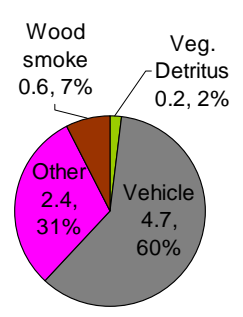

Fig. 12. Apportionment of $\mathrm{OC}\left(\mu \mathrm{gC} \mathrm{am}^{-3}\right)$ for periods within the high fire (filters 1,2$)$ and low fire (filters 3 , 4) periods for (a) fossil $\left(\mathrm{OC}_{\mathrm{f}}\right.$ ) and non-fossil (biomass burning $\mathrm{OC}_{\mathrm{bbnf}}$, other non-fossil $\mathrm{OC}_{\mathrm{onf}}$ ) fractions with dashed lines representing the uncertainty arising from the variability in (OC/EC)bb in the literature, (b) fossil and non-fossil WSOC and WIOC fractions, (c) AMS-PMF sources, and (d) CMB-OMM sources.

\subsection{New data on ${ }^{14} \mathrm{C}$ analysis of Total Carbon (TC) and its fractions}

Four 24-h filter samples were analyzed for the ${ }^{14} \mathrm{C}$ content within elemental (EC) and organic carbon (OC), which were summed to obtain total carbon (TC). OC was further divided into water-soluble (WSOC) and water-insoluble (WIOC) fractions, and analyzed for ${ }^{14} \mathrm{C}$ content as described in Sect. 2.5 above. The first two samples were taken during periods with higher $\mathrm{BBOA}$ and $\mathrm{CH}_{3} \mathrm{CN}$, whereas the later two were from periods with lower fire tracers, and consistent with the "fire periods" described above. Henceforth, we will refer to the average of the first two and last two samples as the "high BB" and "low BB" periods, respectively.

The TC non-fossil fractions range from an average of $41 \%$ during the high $\mathrm{BB}$ period to $28 \%$ during the low $\mathrm{BB}$ period. EC (average: $27 \%$ of TC mass, high fire: $23 \%$, low fire: $31 \%$ ) is dominantly fossil (average: 93\%, high fire: 92\%, low fire: $96 \%$ ). Stone et al. (2008) apportioned $87 \%$ of EC to diesel alone at $\mathrm{T} 0$, and the enhancement of $\mathrm{BC}$ during the high fire periods described above was only $12 \%$, both of which support that EC is dominated by anthropogenic sources at $\mathrm{T} 0$.

OC dominates TC mass (77\% and $69 \%$ of the TC mass during the high and low BB periods, respectively) and has important contributions from non-fossil sources, $51 \%$ and $38 \%$ during the high and low BB periods, respectively (Fig. 12a). Stone et al. (2008) reported that at least $50 \%$ of $\mathrm{OC}$ at $\mathrm{T} 0$ was due to fossil sources by CMB analysis (gasoline, diesel and smoking vehicle emissions), while the fossil vs. non-fossil apportionment of the "Other OC" CMB fraction is unclear.

OC then is divided into fossil $\left(\mathrm{OC}_{\mathrm{f}}\right), \mathrm{BB}$ non-fossil $\left(\mathrm{OC}_{\mathrm{bbnf}}\right.$, accounting for the bomb radiocarbon as discussed by Szidat et al., 2004a), and "other non-fossil OC" $\left(\mathrm{OC}_{\text {onf }}\right)$ (Fig. 12a). The $\mathrm{OC}_{\text {bbnf }}$ concentration is higher in the high BB period, although its fraction remains constant at $13 \%$ of the OC during both periods, which is of the same order as the relative contributions determined by the AMS-PMF and CMB-OMM methods. The "other non-fossil" fraction of OC is $38 \%$ and $25 \%$ in the high and low BB periods respectively. Some of the difference between the periods may be due to higher $\mathrm{BB}$ contribution during the first period than calculated here based on the estimated $(\mathrm{EC} / \mathrm{OC})_{\mathrm{BB}}$, and also to the limited precision/accuracy of the measurements, given that only four samples are involved.

The still substantial fraction of non-fossil carbon in OC (38\%) during the low BB periods suggests the potential importance of urban sources of modern carbon such as food cooking, brake wear, resuspended dust etc. (Hildemann et al., 1994; Christian et al., 2010). Regional sources of modern carbon may also be important. Although biogenic VOCs were very low inside Mexico City during MILAGRO (de Gouw et al., 2009) and even the isoprene measured at T0 is likely to arise from anthropogenic sources (Hodzic et al., 2009), biogenic SOA from the coastal mountain ranges is estimated to have made a contribution of the order of $1-1.5 \mu \mathrm{g} \mathrm{am}^{-3}$ to the regional background at $\mathrm{T} 0$ during MILAGRO (Hodzic et al., 2009). BB from far away sources that show less of a downward trend on the fire 
counts (Fig. S1 http://www.atmos-chem-phys.net/10/5315/ 2010/acp-10-5315-2010-supplement.pdf) would be a possible contributor in principle, however this impact is nevertheless limited by the low concentration of the long-lived fire tracer $\mathrm{CH}_{3} \mathrm{CN}$ during the "low $\mathrm{BB}$ " period, as well as by the low modeled fire impact during $\mathrm{F} 3$.

Figure $12 \mathrm{~b}$ divides OC into WSOC and WIOC, and their respective fossil and non-fossil contributions. Most fossil OC is water-insoluble, $79 \%$ on average. This is likely due to a dominant fossil contribution to HOA/Vehicle POA, although the AMS HOA could include some insoluble POA from non-fossil sources such as food cooking (Mohr et al., 2009). The high fraction of $\mathrm{WIOC}_{\mathrm{f}}$ also suggests that some of the SOA from fossil sources is water-insoluble, consistent with results by Favez et al. (2008) based on measurements in Cairo. Non-fossil OC is almost equally divided on average between WSOC (49\%) and WIOC (51\%). BBOA is typically mostly water-soluble (Sannigrahi et al., 2006; Sullivan et al., 2008), and the large fraction of non-fossil $\mathrm{WIOC}_{\mathrm{nf}}$ $\left(\sim \mathrm{WSOC}_{\mathrm{nf}}\right)$ again points to other less well characterized sources of non-fossil carbon in Mexico City. Although the definition of WSOC is operational, all of these studies measured it under high water/WSOC ratios (high dilution) and thus the results should be approximately comparable.

Vay et al. (2009) suggested a possible impact of "hot" sources which are enriched in ${ }^{14} \mathrm{C}$ to $\mathrm{CO}_{2}$ levels in the Mexico City region. The impact of such hot sources onto organic aerosol measurements has been anecdotally reported in the past based on individual samples which had an unrealistically high non-fossil fraction. However the possibility of a small impact over a larger number of samples has not been studied to our knowledge and could perhaps make a contribution to the high levels of non-fossil carbon during the low BB periods reported here. Aerosol ${ }^{14} \mathrm{C}$ measurements with much higher time-resolution than $24 \mathrm{~h}$ are critical to evaluate this potential contamination and other potential ${ }^{14} \mathrm{C}$ measurement issues in future studies.

The non-fossil carbon fractions of TC reported here are substantially lower than those of Marley et al. (2009), who report $63 \%$ and $43 \%$ modern carbon fractions for the same periods (with an average of $60 \%$ and a range of $42-75 \%$ for TC as the modern fraction at T0 during the AMS sampling period). However, both ours and the Marley et al., datasets result in the high $\mathrm{BB}$ period having a modern $\mathrm{TC}$ fraction that is $\sim 15 \%$ (absolute) higher than that of the low BB period, consistent with the fraction of the $\mathrm{OC}$ apportioned to the fires near Mexico City with all other methods.

A possible source for the discrepancy between the two datasets may be the different size cuts $\left(\mathrm{PM}_{10}\right.$ for the data reported here vs. $\mathrm{PM}_{1}$ for the Marley et al., data). However there was very little $\mathrm{OC}$ in coarse particles between $\mathrm{PM}_{2.5}$ and $\mathrm{PM}_{10}$ at $\mathrm{T} 0\left(0.5 \mu \mathrm{g} \mathrm{m}^{-3}\right.$ or only $3.8 \%$ of the $\mathrm{OC}$ in $\left.\mathrm{PM}_{10}\right)$ (Querol et al., 2008). In addition, many sources of supermicron OC such as vegetative detritus (which was detected in Mexico City; Stone et al., 2008), fungal spores (which are es- timated to account on average for $0.5 \mu \mathrm{g} \mathrm{m}^{-3}$ of coarse PM in the Mexico City region, Heald and Spracklen, 2009), paved road dust, and brake wear have a large fraction of modern OC (Hildemann et al., 1994). Thus, the difference in size cuts appears unlikely to explain the discrepancies between both datasets. Thus the reasons for the observed disagreement are unclear, and future measurements of the non-fossil carbon fraction of Mexico City aerosols as well as intercomparisons of ${ }^{14} \mathrm{C}$ field measurements from different laboratories are highly desirable.

We now perform the same "fire-period analysis" described in Sect. 3.2.2 with the non-fossil carbon data, as shown in Fig. 10d, e, f. Both sets of ${ }^{14} \mathrm{C}$ measurements show an enhancement of non-fossil carbon in all fractions of both datasets during the high fire periods. The concentration of non-fossil TC is on average 34\% for our dataset vs. $60 \%$ for the Marley et al. (2009) dataset, however, both have an enhancement of $\sim 15 \%$ for the high BB period.

Non-fossil EC and OC (from our dataset, Fig. 10e) are enhanced by $4 \%$, and $13 \%$ (absolute), respectively. The change in EC, while a small fractional difference, still results in $92 \%$ of the EC being from fossil fuel sources during the high fire period, consistent with the similar BC concentration during period F2 (high fire) vs. F3 (low fire). The main change in the non-fossil carbon fraction of the TC ( $41 \%$ vs. $28 \%$ non-fossil carbon for the high vs. low fire periods in our dataset) is due to the higher non-fossil OC. Note that the WSOC mass has a $84 \%$ enhancement during the fire period, but that the fraction non-fossil remains relatively constant $(0.67$ high fire vs. 0.65 low fire), while the WIOC has a smaller enhancement (15\%), yet the non-fossil fraction increases by $73 \%$ (Fig. 10f). This suggests that the BBOA impacts both the WSOC and WIOC. Since the fire tracers are much lower during F3 it is clear that other urban and regional sources of non-fossil carbon must exist in order to explain the large fractions of non-fossil carbon measured during this low fire period, as discussed above.

\subsection{Comparison of ${ }^{14} \mathrm{C}$ results with AMS-PMF and CMB-OMM results}

In this section the ${ }^{14} \mathrm{C}$ apportionment results presented in the previous section are compared with those from Chemical Mass Balance of Organic Molecular Markers (CMB-OMM) (Stone et al., 2008) and from the PMFAMS method (Aiken et al., 2009). Since it is unclear what $\mathrm{OA} / \mathrm{OC}$ ratios should be used to convert the different $\mathrm{OC}$ fractions from the ${ }^{14} \mathrm{C}$ analysis into $\mathrm{OA}$, for comparison purposes AMS OA was converted to OC using the OA/OC factors measured by Aiken et al. (2009). Figure S11 (http://www.atmos-chem-phys.net/10/5315/2010/ acp-10-5315-2010-supplement.pdf) shows that the OC from the different datasets is in reasonable agreement. Figure 12c$\mathrm{d}$ shows the averages for the same high and low BB periods used in the ${ }^{14} \mathrm{C}$ apportionment. The correspondence between the PMF/CMB components and WSOC/WIOC frac- 
tions is complex since OOA/SOA is likely distributed into both fractions (Kondo et al., 2007; Favez et al., 2008) and the WSOC/WIOC separation is likely strongly methoddependent. BBOA is a mixture of WSOC and WIOC, with the former typically dominating (Sannigrahi et al., 2006; Sullivan et al., 2008). Most HOA is thought to be WIOC from sources such as vehicle exhaust, but some of it may be nonfossil from sources such as food cooking (Mohr et al., 2009). As discussed by Aiken et al. (2009), AMS-PMF and CMBOMM compare well although with more scatter for shorter averages, as evidenced in Fig. 12c,d for the comparisons for both 2-day ${ }^{14} \mathrm{C}$ sampling averages. The high $\mathrm{BB}$ periods have 14\%-18\% BBOC/woodsmoke OC (from CMB-OMM) vs. 4-7\% for the low BB periods, which is consistent with the $13 \%$ enhancement of the total non-fossil OC, within the uncertainties of all the methods. The one estimate that appears inconsistent is the $\mathrm{OC}_{\mathrm{bbnf}}$ estimated from the $\mathrm{EC}_{\mathrm{nf}}$, which shows a smaller difference than expected between the two periods. The reasons for this small variation are unclear, but may be related to limited precision/accuracy of the $\mathrm{EC}_{\mathrm{nf}}$ quantification over the limited number of samples available.

Figure 13 summarizes the enhancements of carbonaceous aerosol during the high $(\mathrm{F} 1+\mathrm{F} 2)$ over the low $(\mathrm{F} 3)$ fire periods with the three different methods, which are not directly quantitatively comparable as the periods of available data vary with each method. Figure 13 uses all available data which overlaps with the high and low fire periods for each of the measurements. The comparison restricted to the ${ }^{14} \mathrm{C}$ periods is already shown in Fig. 12, and as broad a comparison as possible for the MILAGRO period is of interest here. For the AMS results, we also report an upper estimate where we attribute all of the enhancement of HOA during the high fire periods as well as $10 \%$ of the OOA during the high fire periods as being due to BB sources (per earlier discussions), and add them to the AMS BBOA concentration. Note that the BBOA mass is within $0.3 \mu \mathrm{g} \mathrm{am}^{-3}$ of the total AMS OA enhancement while the upper estimate from the AMS data is higher than the total OA enhancement, suggesting that this upper estimate overestimates the fire impact substantially. The AMS enhancements are somewhat higher than the estimated OA enhancement from the CMB-OMM measurements, especially for the CMB woodsmoke estimate. The CMB woodsmoke is estimated from levoglucosan measurements assuming a given BBOA/levoglucosan ratio. This comparison suggests that the ratio used by Stone et al. (2008) may be too low either due to lower source emissions, evaporation, or possibly atmospheric reaction, resulting in an underestimation of the primary BBOA by CMB-OMM. Stone et al. (2009) observed a correlation between the unexplained $\mathrm{OC}$ and levoglucosan, which they interpreted as evidence of SOA from BB emissions. However that correlation may also be explained by an underestimation of primary BBOA with their method. From the ${ }^{14} \mathrm{C}$ measurements, the enhancements range from $0.7-6.0 \mu \mathrm{g} \mathrm{am}^{-3}$ with $\mathrm{OA}_{\text {non-fossil }}$ and the $\mathrm{OA}_{\text {total }}$ enhancements in $\mathrm{PM}_{10}$ being within $1 \mu \mathrm{g} \mathrm{am}{ }^{-3}$ of

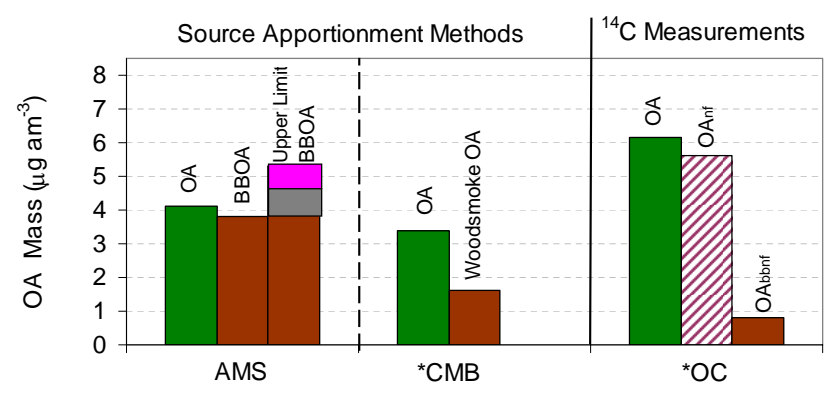

Fig. 13. Enhancement of organic species for the high fire periods versus the low fire period from different source apportionment methods and ${ }^{14} \mathrm{C}$ measurements. Green represents bulk OA, brown represents biomass burning $\mathrm{OA}$, grey and pink represent potential additional BBOA contained in the PMF HOA and OOA respectively, and striped brown is used for the non-fossil ${ }^{14} \mathrm{C}$ measurement. (*Carbon measurements converted to OA using an OA/OC value of 1.6).

each other. Note that the $\mathrm{OA}$ enhancement estimated from the $\mathrm{PM}_{10}$ filters used for ${ }^{14} \mathrm{C}$ analysis is higher than for the $\mathrm{PM}_{2.5} \mathrm{CMB}$ sample, likely explained by a combination of differences in the periods used, the difference in the size cuts, and measurement noise. The enhancement calculated from the $\mathrm{OC}_{\mathrm{bbnf}}$ estimate is much lower than for the other methods, which again suggests that these estimates are less accurate for these MILAGRO data. With that exception, the comparison of most estimates and enhancements indicates a reasonably consistent increased impact of BB of several $\mu \mathrm{gam}^{-3}$ during the high fire periods, and generally within the uncertainties of the different estimates.

\section{Discussion of emission source estimates}

\subsection{Summary of BB contributions to fine $\mathrm{OA}, \mathrm{OC}$, and PM at T0}

Table 1 summarizes the estimated contributions of $\mathrm{BB}$ to $\mathrm{OA}$, $\mathrm{OC}$, and fine PM mass based on the different techniques used in this paper. The AMS average contribution is expressed as a range as discussed in Sect. 3.3, ranging from the AMS BBOA to an upper estimate which includes $10 \%$ of the OOA and $0.75 \mu \mathrm{g} \mathrm{am}^{-3}$ from the HOA during the high fire periods. The average BBOA impact during MILAGRO thus ranges between $15-23 \%$, with estimates of $23-31 \%$ during the high fire period and $3 \%$ during the low fire period. The total OA from BB sources estimated in this way from the AMS is similar to or larger than those from the CMB-OMM and ${ }^{14} \mathrm{C}$ methods as discussed above.

We can also estimate the average contribution of $\mathrm{BB}$ to fine PM by adding the AMS BBOA to the BB fraction of $\mathrm{BC}$ estimated from the non-fossil ${ }^{14} \mathrm{C}$ in $\mathrm{EC}$ (equivalent to $\sim 0.3 \mu \mathrm{g} \mathrm{am}^{-3}$ on average), $10 \%$ of the ammonium nitrate (based on the fact that $\mathrm{HCN}$ explained $10 \%$ of the vari- 
Table 1. Biomass burning contributions to OA, OC, and PM during the high and low fire periods, MILAGRO average, and an estimated annual percentage of fine PM. (AMS+Refractory=AMS+BC+metals+soil).

\begin{tabular}{|c|c|c|c|c|c|c|c|c|c|c|}
\hline & & \multicolumn{3}{|c|}{$\operatorname{Mass}\left(\mu \mathrm{g} \mathrm{am}^{-3}\right)$} & \multicolumn{5}{|c|}{ Percent of Total Mass } & \multirow{2}{*}{$\begin{array}{l}\% \text { of PM Number } \\
\text { Upper end } \\
\text { Accum. Mode }\end{array}$} \\
\hline & & AMS & CMB & ${ }^{14} \mathrm{C}$ & AMS & CMB & ${ }^{14} \mathrm{C}$ & $\begin{array}{l}\text { K-based } \\
\text { (SIMAT) }\end{array}$ & $\begin{array}{l}\text { AMS+ } \\
\text { Refractory }\end{array}$ & \\
\hline \multirow[t]{3}{*}{ OA } & High Fire & $4.3-5.8$ & 2.4 & & $23-31 \%$ & $16 \%$ & & & & \\
\hline & Low Fire & 0.5 & 0.9 & & $3 \%$ & $8 \%$ & & & & \\
\hline & $\begin{array}{l}\text { MILAGRO } \\
\text { Average }\end{array}$ & $2.5-3.6$ & 1.7 & & $15-23 \%$ & $13 \%$ & & & & \\
\hline \multirow[t]{3}{*}{$\mathrm{OC}$} & High Fire & $2.7-3.6$ & 1.5 & 2.0 & $26-35 \%$ & $17 \%$ & $13 \%$ & & & \\
\hline & Low Fire & 0.3 & 0.6 & 1.5 & $4 \%$ & $7 \%$ & $13 \%$ & & & \\
\hline & $\begin{array}{l}\text { MILAGRO } \\
\text { Average }\end{array}$ & $1.6-2.2$ & 1.0 & 1.7 & $17-23 \%$ & $12 \%$ & $13 \%$ & $13-23 \%^{\mathrm{a}}$ & & \\
\hline \multirow[t]{4}{*}{ PM } & High Fire & & & & $19-25 \%$ & & & & $15-19 \%$ & \\
\hline & Low Fire & & & & $3 \%$ & & & & $4 \%$ & \\
\hline & $\begin{array}{l}\text { MILAGRO } \\
\text { Average }\end{array}$ & & & & $11-15 \%$ & & & & $7-9 \%$ & $13-20 \%^{b}$ \\
\hline & $\begin{array}{l}\text { Est. Annual } \\
\text { Average }\end{array}$ & & & & $4-5 \%$ & & & & $2-3 \%$ & \\
\hline
\end{tabular}

${ }^{\mathrm{a}}$ estimate from the results of Gilardoni et al. (2009) after accounting from non-BB K as described in the text. ${ }^{\mathrm{b}}$ estimate from the results of Moffet et al. (2008a) after accounting for non-BB K as described in the text.

ance of ammonium nitrate in aircraft measurements while the correlation with urban-dominated $\mathrm{CO}$ was much higher; DeCarlo et al., 2008) and $10 \%$ of the "soil" (based on the limited correlation between soil and BBOA described in Fig. S10 (http://www.atmos-chem-phys.net/10/5315/2010/ acp-10-5315-2010-supplement.pdf) and discussed above). In doing so we are assuming that the other species are dominated by non-BB sources, which is clearly justified for metals which are dominated by industrial sources (Moffet et al., 2008b), sulfate and the associated ammonium which are dominated by regional sources such as volcanoes, refineries, and power plants (DeCarlo et al., 2008). With these assumptions, BB accounts on average for $7-9 \%$ of the fine PM at T0 during MILAGRO.

\subsection{Further comparisons with Mexico City emissions inventory}

Here we estimate the fractional contribution of BB from the fires in the mountains near Mexico City to the annual average fine PM on the ground in Mexico City. Fire count data indicate that the period sampled by the AMS during MILAGRO had a number of fire counts in the region near Mexico City (within a circle of $120 \mathrm{~km}$ radius) that was $16 \%$ of the annual average for 2000-2006, while RAMA data (http: //www.sma.df.gob.mx/simat/pnrama2.htm) indicate that the $\mathrm{PM}_{2.5}$ during March 2004-2008 is close the annual average $\mathrm{PM}_{2.5}$. If we scale the PM due to $\mathrm{BB}$ to the rest of the year by the fire counts and compare to the annual average, we estimate that $2-3 \%$ of the annual average fine PM is due to these BB sources. Thus, BB from fires in the mountains near the MCMA is an important source of fine PM inside the City during periods of high fire intensity but a minor source for the annual average. Comparing the BB source estimated here to the 2006 MCMA emissions inventory (SMA, 2006), we conclude that the impact of fires on $\mathrm{PM}_{2.5}$ is lower by a factor of $\sim 20$ in the inventory than for our estimate. The inventory attributes $0.7 \%$ of the total $\mathrm{PM}_{2.5}$ attributed to forest fires and is $\sim 3.5$ times too low for the total primary urban sources (Aiken et al., 2009), compared with our estimate of $2-3 \%$ of the actual primary sources. However we note that many of the fire counts occur just outside of the MCMA inventory region, which suggests the importance of expanding the inventory activity over a larger area, given the impact of these sources on MCMA air quality. The impact of forest fire emissions on health in Mexico City is uncertain but may be somewhat larger than the impact on the annual average, due to the influence of plumes with very high particle concentrations. 

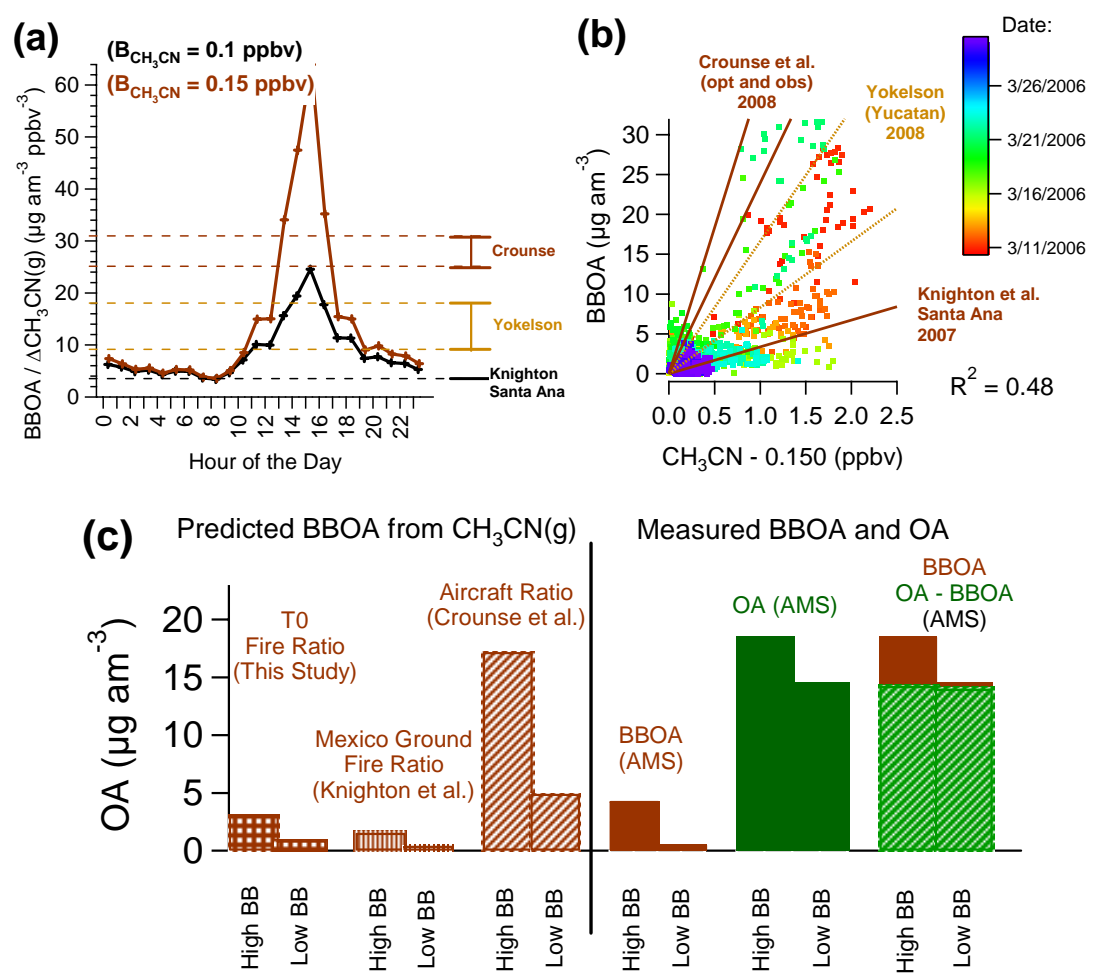

Fig. 14. (a) Diurnal profile of BBOA divided by $\triangle \mathrm{CH}_{3} \mathrm{CN}$ at $\mathrm{T} 0$ (assuming two different backgrounds), to the right the range of values reported by Crounse et al. (2009), Yokelson et al. (2009), and Knighton et al. (2007) are shown; (b) scatter plot of BBOA vs. $\mathrm{CH}_{3} \mathrm{CN}$ at T0, with lines representing the same previous studies; (c) left: predicted BBOA from $\mathrm{CH} 3 \mathrm{CN}$ and different emission ratios for the high fire and low fire periods, right: measured BBOA and OA for the same periods. The BBOA/ $\Delta \mathrm{CH}_{3} \mathrm{CN}$ values $\left(\mu \mathrm{g} \mathrm{am}^{-3} \mathrm{ppbv}-1\right) \mathrm{used}$ are as follows: This study (6.0), Knighton (3.4), Crounse (37).

\subsection{Comparison with Aircraft-based Estimates}

\subsubsection{Comparison of measured BBOA to nitrile tracer-based estimates}

It is of interest to compare our results to those from Crounse et al. (2009), which estimated BBOA above Mexico City during several afternoon flights to be $\sim 52 \%$ of the OA measurement of $11.5 \mu \mathrm{g} \mathrm{am}^{-3}$ (i.e. $\sim 6 \mu \mathrm{g} \mathrm{am}^{-3}$ ). Their analysis includes several flights in early March when the fires were somewhat more intense than the period of our analysis at $\mathrm{T} 0$. These authors also show that the relative impact of BB is $50 \%$ lower at the ground than aloft during their afternoon measurements, and as such, their results are not inconsistent with the $4.3 \mu \mathrm{g} \mathrm{am}^{-3}$ of BBOA at the ground during high-fire periods and $2.5 \mu \mathrm{g} \mathrm{am}^{-3}$ for the T0 sampling average.

A diurnal cycle of the ratio of AMS BBOA to excess gasphase acetonitrile (above background) is shown in Fig. 14a, along with a scatter plot of both quantities in Fig. 14b. There is correlation between the two species $\left(R^{2}=0.48\right)$, but with substantial variability and a strong diurnal cycle for this ratio, which could be due to several reasons. First, the ratio of $\mathrm{OA} / \triangle \mathrm{CH}_{3} \mathrm{CN}$ may be variable across different $\mathrm{BB}$ sources (forest fires, agricultural fires, urban burning, etc.) as reported for Mexico City by Knighton et al. (2007) and for a larger set of open BB sources by Andreae and Merlet (2001). Second, there are sources of $\mathrm{CH}_{3} \mathrm{CN}$ in Mexico City that are not correlated with $\mathrm{HCN}$ or OA emissions. Indeed, Crounse et al. (2009) report that "on multiple occasions, directly over Mexico City, enhanced $\mathrm{CH}_{3} \mathrm{CN}$ was observed without accompanying enhancements in $\mathrm{HCN}$," and we observed similar plumes of $\mathrm{CH}_{3} \mathrm{CN}$ without increases in OA during MCMA-2003. Third, there may be remaining unsubtracted interferences in the PTRMS detection of acetonitrile, given the high levels and complexity of VOCs in Mexico City (Velasco et al., 2007). A known interference from ethyl acetate was subtracted from the raw data and amounted to about $15 \%$ of the average $\mathrm{CH}_{3} \mathrm{CN}$ concentration, but perhaps other interferences remain. To further explore the variability of the ratios for forest fire emissions, we include Table 2, which contains results from previous studies of fires and urban areas in comparison to the T0 data. All ratios are in STP. When compared with direct forest fire emissions, the ratios measured at $\mathrm{T} 0$ suggest an important fire impact. BBOA to acetonitrile ratios reach $29 \mu \mathrm{g} \mathrm{sm}^{-3} \mathrm{ppbv}^{-1}$ (higher if a 150 pptv background is used for $\mathrm{CH}_{3} \mathrm{CN}$ instead of $100 \mathrm{pptv}$ ), whereas wildfires measured directly from 
Table 2. Emission ratios from forest fire sources and measurements impacted by them measured both on the ground and by aircraft. (*: evaluated only for points with $\mathrm{BBOA}>10 \mu \mathrm{g} \mathrm{am}^{-3}$ and using a background of $100 \mathrm{pptv}$ for acetonitrile). Particulate measurements, i.e. BBOA, are under STP $\left(\mu \mathrm{g} \mathrm{sm}^{-3}\right)$ for ease of comparison to other locations.

\begin{tabular}{|c|c|c|c|c|c|c|}
\hline Campaign: & Location: & Reference: & $\begin{array}{l}\mathrm{BBOA} / \mathrm{CH}_{3} \mathrm{CN} \\
\left(\mu \mathrm{g} \mathrm{sm}^{-3} / \mathrm{ppbv}\right)\end{array}$ & $\begin{array}{l}\mathrm{BBOA} / \mathrm{CO} \\
\left(\mu \mathrm{g} \mathrm{sm}^{-3} / \mathrm{ppmv}\right)\end{array}$ & $\begin{array}{l}\mathrm{CH}_{3} \mathrm{CN} / \mathrm{CO} \\
\text { (ppbv/ppmv) }\end{array}$ & $\begin{array}{l}\mathrm{HCN} / \mathrm{CO} \\
\text { (ppbv/ppmv) }\end{array}$ \\
\hline NEAQS & New York & de Gouw et al., 2006 & & & 0.25 & \\
\hline NEAQS & Alaska Fire & de Gouw et al., 2006 & & & 1.3 .3 & \\
\hline FLAME & Lab Studies & Knighton et al., 2007 & $2-330$ & $2.1-700$ & $0.76-3.4$ & $2.0-9.6$ \\
\hline MILAGRO & T0 & This Study & $8.5-29 *$ & $1.6-50$ & $\sim 0.13-2.4$ & \\
\hline MILAGRO & $\mathrm{T} 1$ & de Gouw et al., 2008 & & & $0.1-1.0$ & \\
\hline MILAGRO & Santa Ana Fire & Knighton et al., 2007 & 4.8 & 11 & 2.6 & 5.2 \\
\hline MILAGRO & T0 & Knighton et al., 2007 & & 1 & 0.75 & \\
\hline MILAGRO & Regional Fires & Crounse et al., 2009 & $34-52$ & 160 & $3.6-4.0$ & $8.5-9.6$ \\
\hline MILAGRO & Urban Area & Crounse et al., 2009 & $0.23-0.27$ & 0.6 & & \\
\hline MILAGRO & Mexico Fires & DeCarlo et al., 2008 & $\sim 40$ & $150-200$ & & \\
\hline MILAGRO & Mexico Fires & Yokelson et al., 2007 & $\sim 133$ & 12.8 & & \\
\hline MILAGRO & Yucatan Fires & Yokelson et al., 2009 & $12-24$ & $50-100$ & $\sim 2.6$ & 6.1 \\
\hline
\end{tabular}

aircraft by Crounse et al. (2009) had similar ratios. However, there is a wide range of observed $\mathrm{BBOA} / \Delta \mathrm{CH}_{3} \mathrm{CN}$ ratios at T0, which may be due to the reasons listed above. Specifically a clear pattern emerges in the diurnal cycle of the $\mathrm{BBOA} / \Delta \mathrm{CH}_{3} \mathrm{CN}$ ratio in Fig. 14a, for which a much larger ratio is apparent in the afternoon (when the fire counts are highest, see Fig. 15a) compared to the morning when BBOA is largest. Thus the variability of the diurnal cycle of this ratio explains why the method of estimating BBOA from $\Delta \mathrm{CH}_{3} \mathrm{CN}$ using the constant ratios measured in the afternoon fires is not applicable for the 24-h averages at T0. In other words, if the afternoon $\mathrm{BBOA} / \triangle \mathrm{CH}_{3} \mathrm{CN}$ ratios where also applicable in the morning and one estimated BBOA from the measured $\triangle \mathrm{CH}_{3} \mathrm{CN}$, all the $\mathrm{OA}$ observed in the mornings would be BBOA with no room for other sources such as vehicle exhaust etc., which is clearly unreasonable.

It is also of interest to compare the BBOA estimated here with what would be inferred by applying a method similar to that of Crounse et al. (2009) to the T0 data, in which an estimate of $\mathrm{BBOA}$ is derived from the measured $\mathrm{CH}_{3} \mathrm{CN}$ and the $\mathrm{BBOA} / \triangle \mathrm{CH}_{3} \mathrm{CN}$ ratio inferred from the aircraft measurements. Figure 14c shows the estimate of BBOA based on this method for the high and low fire periods (F1+F2 vs. F3) using several BBOA/ $\triangle \mathrm{CH}_{3} \mathrm{CN}$ ratios, as well as the AMS $\mathrm{OA}$, and the AMS BBOA and OA-BBOA for the same periods. If the ratio derived from the Crounse et al. (2009) data was applicable to our T0 data, all of the OA measured at T0 during the high fire periods would be BBOA (which is very unrealistic due to the known important urban sources of $\mathrm{OA}$ and the results of the apportionment methods discussed above), and thus we would expect very little total OA during the low-fire period. In practice OA shows a much smaller decrease during the low-fire period, which is instead consistent with the BBOA estimated from PMF-AMS, CMB-OMM, and ${ }^{14} \mathrm{C}$ increases. When a $\mathrm{BBOA} / \mathrm{CH}_{3} \mathrm{CN}$ ratio about $1 / 4$ of that of derived from Crounse et al. (2009) is used, the predicted BBOA is consistent with the T0 results. The possible reasons for the lack of applicability of the higher ratio to our data are those mentioned above on the discussion of the $\mathrm{BBOA}$ vs. $\mathrm{CH}_{3} \mathrm{CN}$ scatter plot. Our results imply that caution must be applied when extrapolating emission ratios observed at specific sources and times across a complex area such as the MCMA where many emission sources are active across a diurnal cycle.

\subsubsection{Surface concentrations vs. column-integrated OA amounts}

To illustrate the differences between the averages of surface concentrations and column-integrated amounts and following Hodzic et al. (2009), we show in Fig. 15 the diurnal cycles of both parameters for the AMS total OA, $\mathrm{OA}$ components, and non-refractory (NR) $\mathrm{PM}_{1}+\mathrm{BC}$. The column-integrated amounts have been estimated by multiplying the surface concentrations by the boundary layer (BL) depths measured by Shaw et al. (2007), which assumes a constant concentration across the depth of the BL. Figure S12 (http://www.atmos-chem-phys.net/10/5315/ 2010/acp-10-5315-2010-supplement.pdf) shows the same analysis including the inorganic and refractory components. Surface concentrations are the most relevant parameter for health effects on the MCMA population, while columnintegrated amounts are more directly relevant to impacts on regional visibility and climate. There are dramatic differences between the two parameters for the different species: while the surface concentrations of OA, BBOA, and NR $\mathrm{PM}_{1}+\mathrm{BC}$ are dominated by the higher overnight and morning levels, their column amounts are much larger in the afternoon, when substantial concentrations are still present despite a very large growth of the PBL. Note that in this 

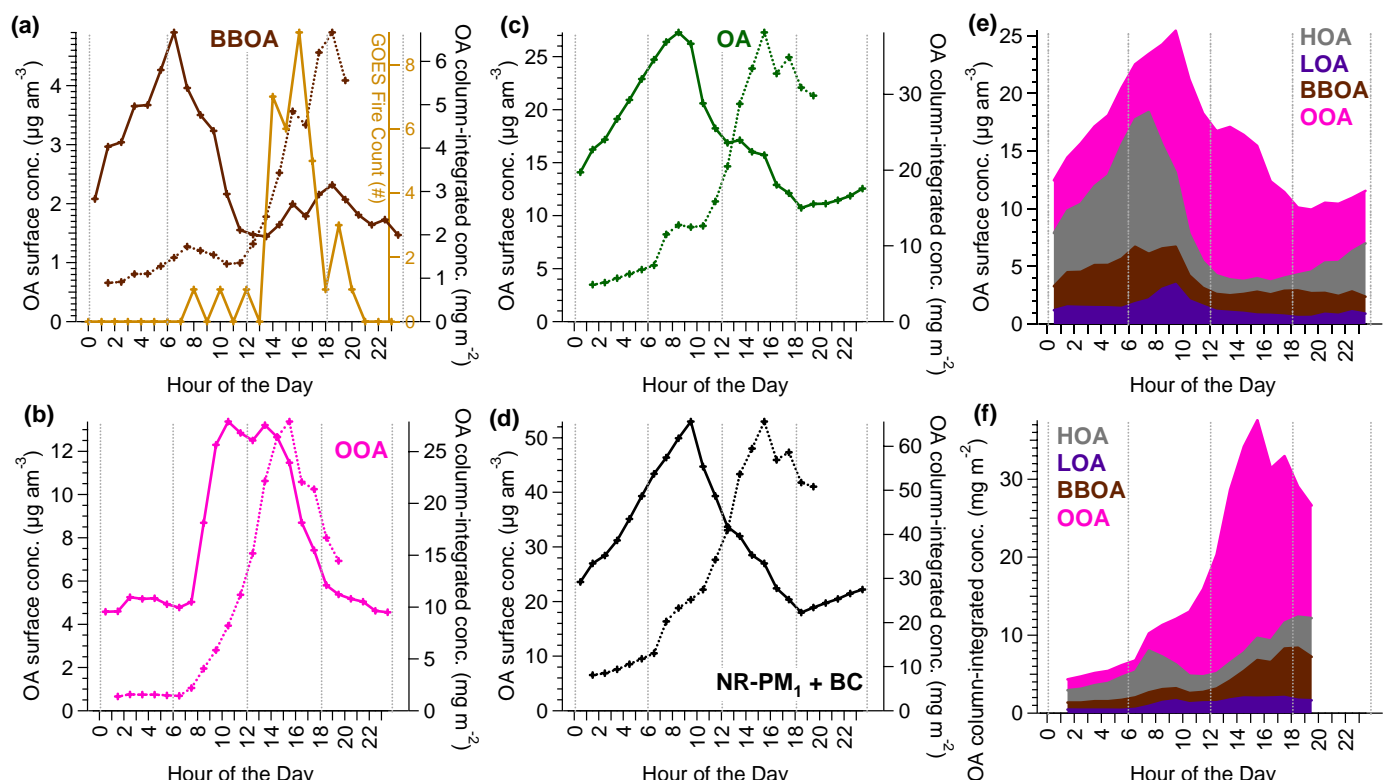

Fig. 15. (a-d) Diurnal profiles of the concentrations (solid) and estimated column-integrated amounts (dashed) for BBOA, OOA, OA, and $\mathrm{NR}-\mathrm{PM}_{1}+\mathrm{BC}$, column amounts are in $\mathrm{mg} \mathrm{m}^{-2}$; (e) stacked plot of the diurnal cycles of the concentrations of the OA components; (f) stacked plot of the diurnal cycles of the estimated column amounts of the OA components.

analysis we have neglected the species present above the boundary layer in the morning, as prior studies have found limited pollution in residual layers, especially when compared with the morning emissions (see e.g. Fig. 1 of Herndon et al., 2008).

The impact of the afternoon fires is very apparent on the BBOA column amount even though it is harder to discern on the BBOA surface concentration due to the dilution of the emissions on the very deep boundary layer (Fig. 15a). The BBOA column impact is likely larger than represented here, due to the higher fractional contribution of $\mathrm{BB}$ at higher altitudes as reported by Crounse et al. (2009). In contrast with the other components, OOA was already larger in the late morning and early afternoon before the fires were active. The column amount (Fig. 15f) dramatically shows the dominant importance of OOA for the aerosol export from the MCMA, consistent with the dominance of OOA in OA over regional scales observed at many locations (Zhang et al., 2007, and references therein; Jimenez et al., 2009). HOA and LOA on the other hand show much reduced importance on the column amounts compared to the surface concentrations, as expected for local primary emissions.

\subsection{Summary of evidence relating to SOA from biomass burning}

Grieshop et al. (2009) and Jimenez et al. (2009) have shown that SOA from BB emissions produces similar spectra in the AMS to that of SOA from other sources. Therefore the AMS OOA should be interpreted as total SOA, and infer- ences about the different sources of SOA need to use additional information such as tracers and model results. Here we briefly summarize the evidence relating to the impact of SOA from biomass burning at T0 during MILAGRO:

- The largest impacts from BBOA and $\mathrm{CH}_{3} \mathrm{CN}$ occur in the early morning, which FLEXPART links to emissions from smoldering fires in the late evening and night. These emissions have not undergone photochemical processing and thus not formed SOA. This is consistent with the lack of change of the OOA time series or diurnal cycle during the periods of very elevated BBOA in the early morning.

- The fire period analysis indicates an increase (rather than a decrease) of OOA during the low fire period, and the different fire tracers and model results are correlated with each other but not with OOA. This indicates that the OOA at T0 is dominated by other sources and not SOA from BB emissions.

- The net amount of SOA formed in field studies from wildfire $\mathrm{BB}$ emissions during photochemically active periods has been reported to be variable depending on the source (Capes et al., 2008; de Gouw and Jimenez 2009; Hallquist et al., 2009; Yokelson et al., 2009), varying between negligible and about a doubling of the BB POA. DeCarlo et al. (2010) estimated that the Mexico City fires produced a net amount of SOA equivalent to about $1 / 3$ of the primary BBOA over several hours to a day. If the BBOA present at $\mathrm{T} 0$ during the 
photochemically active period is assumed to be completely primary, we can estimate a net contribution of BB SOA of about $0.5 \mu \mathrm{g} \mathrm{am}^{-3}$, which corresponds to about $7 \%$ of the total OOA at T0.

- The amount of BB SOA estimated in the previous point would represent a larger fraction of the 24-h columnintegrated OOA in Fig. 15f, consistent with the larger impact of BB SOA identified in aircraft studies (DeCarlo et al., 2010).

\section{Conclusions}

In this Part 2 paper we have presented multiple analyses of the impact from regional $\mathrm{BB}$ at the $\mathrm{T} 0$ supersite during MILAGRO. Regional fire counts from satellite data and the fire impacts estimated with the FLEXPART lagrangian dispersion model correlate with AMS BBOA, which indicates that $\mathrm{BBOA}$ is dominated by regional forest fires in the mountains surrounding the MCMA basin. The different fire tracers correlate among themselves, with levoglucosan and levog.-eq. mass having little background, acetonitrile having its well-known tropospheric background of 100$150 \mathrm{pptv}$, and $\mathrm{PM}_{2.5}$ total potassium having a background of $\sim 160 \mathrm{ng} \mathrm{m}^{-3}$. The potassium background, which is not related to BB sources, represents two-thirds of its average concentration. Thus care should be taken not to use total $\mathrm{K}$ as a tracer for BB in a complex environment such as the MCMA where non-BB sources of this species are active, and especially if measurements of water-soluble $\mathrm{K}$ are not available, as otherwise a large overestimation of the fire impacts may result.

We identified three periods, two with high BB impact, and the other with low BB impact. The regional fire impact is about 5 times larger during the high fire periods as indicated by fire counts, FLEXPART-predicted impacts, and fire tracers. Tracers of urban pollution such as $\mathrm{Zn}, \mathrm{Pb}$, or aromatics have similar concentrations during the two periods. BBOA is enhanced by $3.8 \mu \mathrm{g} \mathrm{am}^{-3}$ on average during the high fire impact periods, equating to $\sim 23 \%$ of the OA versus $3 \%$ during the low fire impact period. The CMB estimates are consistent with an impact of this order. Other AMS OA components do not show a correlation with fire counts, tracers, or FLEXPART wildfire impacts.

Non-fossil carbon is higher during the high fire periods by $\sim 15 \%$ for the two available modern carbon measurements, although the difference in their absolute values remains unexplained. The enhancement during the high-fire periods is consistent with the PMF-AMS and CMB-OMM results. The overall contribution of $\mathrm{BB}$ to $\mathrm{OA}$ (or OC) is in the range 12$23 \%$ and for PM is 7-9\%. These estimates are close to the results based on K from Moffet et al. (2008a) and Gilardoni et al. (2009), once the fraction of K due to non-BB sources is taken into account. Important urban or regional non-fire sources of non-fossil carbon (e.g. food cooking, biogenic
SOA) are implied by the substantial non-fossil carbon fraction during the low regional fire period (37\% OC and $30 \%$ of $\mathrm{TC}$ at $\mathrm{T0}$ ). These non-BB modern carbon sources, as well as the possible impact of "hot" sources with high ${ }^{14} \mathrm{C}$ deserve further research.

Dust is also elevated during the high BB period but this appears to be coincidental due to the drier conditions, and not driven by direct dust emission by the fires. Overall, the fires from the region near the MCMA are estimated to contribute $15-23 \%$ of the OA and $7-9 \%$ of the fine PM at T0 during MILAGRO, and 2-3\% of the fine PM as an annual average. The 2006 MCMA inventory contains a far lower impact of the forest fire emissions, although a fraction of these emissions occur just outside of the MCMA inventory area.

Finally, we show that the ambient BBOA/ $\triangle \mathrm{CH}_{3} \mathrm{CN}$ ratio is much higher in the afternoon under the direct forest fire impact than during the rest of the day. The reasons for the lower ratio during the morning when BBOA concentrations are highest are unclear, and may be related to different source ratios, the influence of non-BB sources for $\mathrm{CH}_{3} \mathrm{CN}$, or perhaps remaining interferences on this measurement. When we account for the variation in the diurnal cycle of $\mathrm{BBOA} / \Delta \mathrm{CH}_{3} \mathrm{CN}$, we show that our results can be made consistent with those of Crounse et al. (2009) for several afternoon flights during MILAGRO. The lesson from these comparisons is that caution is warranted before applying emission ratios derived at single sources across a complex urban area such as the MCMA. Finally we show that there are large differences in the contributions of the different OA components to the surface concentrations vs. integrated column amounts: BBOA and OOA columns and export from the MCMA are dominated by the afternoons, while HOA and LOA are important for the surface concentrations but much less so for the export of pollution from the MCMA. The very large contribution of secondary species to the afternoon columns is consistent with the recent results of ParedesMiranda et al. (2009). These surface vs. column comparisons highlight the limitations of aircraft studies for source apportionment of ground receptors inside urban areas, and their power for regional climate and visibility impacts.

Acknowledgements. This study was supported by the following funding, NASA: fellowship NNG04GR06H (ACA), NNG05GQ50H (IMU); NSF: grants ATM-0528634 and ATM0449815 (CAREER), ATM-0810950 (BDF), ATM-0511803 (BDF and LTM), ATM-0511769 (WPA and GPM), ATM-0528227 (LTM); DOE BER-ASP program: grants DE-FG02-05ER63981 and DE-FG02-05ER64008 (WPA and GPM); EPA STAR fellowship RD-83216101-0 (PFD), and Knut and Alice Wallenberg Foundation (JN). Although this research has been partially funded by EPA and NSF, it has not been subject to Agency Review and thus no official endorsement should be inferred. We would like to thank Alma Hodzic for providing the PBL data, and support from and useful discussions with D. Salcedo, Aerodyne and Tofwerk personnel, J. de Gouw, and the remainder of the Jimenez Group. We are grateful to E. Vogel and M. Ruff (University of 
Berne) for their support of the ${ }^{14} \mathrm{C}$ analyses, N. Perron (PSI) for OC/EC concentration measurements, the CENICA team for high-volume sampling and T. Gustafsson, J. Petterson (University of Gothenburg) and K. Gäggeler (PSI) for transfer of filter samples to Switzerland. PIXE analysis was done at the Environmental Molecular Sciences Laboratory, a US DOE national user facility located at Pacific Northwest National Laboratory. Finally, we would like to acknowledge IMP for hosting T0 supersite and the logistical support from many Mexican government agencies and institutions which made it possible to carry out the MCMA-2006/MILAGRO Campaign.

Edited by: S. Madronich

\section{References}

Aiken, A. C., DeCarlo, P. F., Kroll, J. H., et al.: O/C and OM/OC Ratios of Primary, Secondary, and Ambient Organic Aerosols with High-Resolution Time-of-Flight Aerosol Mass Spectrometry, Environ. Sci. Technol., 42, 4478-4485, doi:4410.1021/es703009q, 2008.

Aiken, A. C., Salcedo, D., Cubison, M. J., Huffman, J. A., DeCarlo, P. F., Ulbrich, I. M., Docherty, K. S., Sueper, D., Kimmel, J. R., Worsnop, D. R., Trimborn, A., Northway, M., Stone, E. A., Schauer, J. J., Volkamer, R. M., Fortner, E., de Foy, B., Wang, J., Laskin, A., Shutthanandan, V., Zheng, J., Zhang, R., Gaffney, J., Marley, N. A., Paredes-Miranda, G., Arnott, W. P., Molina, L. T., Sosa, G., and Jimenez, J. L.: Mexico City aerosol analysis during MILAGRO using high resolution aerosol mass spectrometry at the urban supersite (T0) - Part 1: Fine particle composition and organic source apportionment, Atmos. Chem. Phys., 9, 66336653, doi:10.5194/acp-9-6633-2009, 2009.

Alfarra, M. R., Coe, H., Allan, J. D., et al.: Characterization of urban and rural organic particulate in the lower Fraser valley using two aerodyne aerosol mass spectrometers, Atmos. Environ., 38, 5745-5758, 2004.

Andreae, M. O. and Merlet, P.: Emission of trace gases and aerosols from biomass burning. Global Biogeochem. Cy. 15, 955-966, 2001.

Bond, T. C., Streets, D. G., Yarber, K. F., et al.: A technologybased global inventory of black and organic carbon emissions from combustion, J. Geophys. Res.-Atmos., 109, D14203, doi:10.1029/2003JD003697, 2004.

Bravo, A. H., Sosa, E. R., Sanchez, A. P., et al.: Impact of wildfires on the air quality of Mexico City, 1992-1999, Environ. Pollut., 117, 243-253, 2002.

Canagaratna, M. R., Jayne, J. T., Jimenez, J. L., et al.: Chemical and microphysical characterization of ambient aerosols with the aerodyne aerosol mass spectrometer, Mass Spectrom. Rev., 26, 185-222, 2007.

Capes, G., Johnson, B., McFiggans, G., et al.: Aging of biomass burning aerosols over West Africa: Aircraft measurements of chemical composition, microphysical properties, and emission ratios, J. Geophys. Res., 113, D00C15, doi:10.1029/2008JD009845, 2008.

Caseiro, A., Bauer, H., Schmidl, C., et al.: Wood burning impact on PM10 in three Austrian regions, Atmos. Environ., 43, 21862195, 2009.
Chow, J. C., Watson, J. G., Edgerton, S. A., et al.: Chemical composition of $\mathrm{PM}_{2.5}$ and $\mathrm{PM}_{10}$ in Mexico City during winter 1997, Sci. Total Environ., 287, 177-201, 2002.

Christian, T. J., Yokelson, R. J., Crdenas, B., Molina, L. T., Engling, G., and Hsu, S.-C.: Trace gas and particle emissions from domestic and industrial biofuel use and garbage burning in central Mexico, Atmos. Chem. Phys., 10, 565-584, doi:10.5194/acp-10565-2010, 2010.

Crounse, J. D., DeCarlo, P. F., Blake, D. R., Emmons, L. K., Campos, T. L., Apel, E. C., Clarke, A. D., Weinheimer, A. J., McCabe, D. C., Yokelson, R. J., Jimenez, J. L., and Wennberg, P. O.: Biomass burning and urban air pollution over the Central Mexican Plateau, Atmos. Chem. Phys., 9, 4929-4944, doi:10.5194/acp-9-4929-2009, 2009.

Cubison, M. K., Sueper, D., Dunlea, E., et al.: Submicron Aerosol Composition during the ARCTAS campaign: Arctic Haze, Biomass Burning, and California Pollution, Eos Trans. AGU 89, Fall Meet. Suppl., Abstract A11A-0081, 2008.

de Foy, B., Fast, J. D., Paech, S. J., Phillips, D., Walters, J. T., Coulter, R. L., Martin, T. J., Pekour, M. S., Shaw, W. J., Kastendeuch, P. P., Marley, N. A., Retama, A., and Molina, L. T.: Basinscale wind transport during the MILAGRO field campaign and comparison to climatology using cluster analysis, Atmos. Chem. Phys., 8, 1209-1224, doi:10.5194/acp-8-1209-2008, 2008.

de Foy, B., Zavala, M., Bei, N., and Molina, L. T.: Evaluation of WRF mesoscale simulations and particle trajectory analysis for the MILAGRO field campaign, Atmos. Chem. Phys., 9, 44194438, doi:10.5194/acp-9-4419-2009, 2009.

de Gouw, J. and Jimenez, J. L.: Organic Aerosols in the Earth's Atmosphere. Environ. Sci. Technol 43, 7614-7618, doi:7610.1021/es9006004, 2009.

de Gouw, J. A., Welsh-Bon, D., Warneke, C., Kuster, W. C., Alexander, L., Baker, A. K., Beyersdorf, A. J., Blake, D. R., Canagaratna, M., Celada, A. T., Huey, L. G., Junkermann, W., Onasch, T. B., Salcido, A., Sjostedt, S. J., Sullivan, A. P., Tanner, D. J., Vargas, O., Weber, R. J., Worsnop, D. R., Yu, X. Y., and Zaveri, R.: Emission and chemistry of organic carbon in the gas and aerosol phase at a sub-urban site near Mexico City in March 2006 during the MILAGRO study, Atmos. Chem. Phys., 9, 3425-3442, doi:10.5194/acp-9-3425-2009, 2009.

DeCarlo, P. F., Dunlea, E. J., Kimmel, J. R., Aiken, A. C., Sueper, D., Crounse, J., Wennberg, P. O., Emmons, L., Shinozuka, Y., Clarke, A., Zhou, J., Tomlinson, J., Collins, D. R., Knapp, D., Weinheimer, A. J., Montzka, D. D., Campos, T., and Jimenez, J. L.: Fast airborne aerosol size and chemistry measurements above Mexico City and Central Mexico during the MILAGRO campaign, Atmos. Chem. Phys., 8, 4027-4048, doi:10.5194/acp8-4027-2008, 2008.

DeCarlo, P. F., Kimmel, J. R., Trimborn, A., et al.: Fielddeployable, high-resolution, time-of-flight aerosol mass spectrometer, Anal. Chem. 78, 8281-8289, 2006.

DeCarlo, P. F., Ulbrich, I. M., Crounse, J., de Foy, B., Dunlea, E. J., Aiken, A. C., Knapp, D., Weinheimer, A. J., Campos, T., Wennberg, P. O., and Jimenez, J. L.: Investigation of the sources and processing of organic aerosol over the Central Mexican Plateau from aircraft measurements during MILAGRO, Atmos. Chem. Phys. Discuss., 10, 2445-2502, doi:10.5194/acpd10-2445-2010, 2010.

Docherty, K. S., Stone, E. A., Ulbrich, I. M., et al.: Appor- 
tionment of primary and secondary organic aerosols in southern California during the 2005 study of organic aerosols in Riverside (SOAR), Environ. Sci. Technol., 42, 7655-7662, doi:7610.1021/es8008166, 2008.

Dockery, D. W., Pope, C. A., Xu, X. P., et al.: An Association between Air-Pollution and Mortality in 6 United-States Cities. New Engl. J. Med. 329, 1753-1759, 1993.

Dzepina, K., Volkamer, R. M., Madronich, S., Tulet, P., Ulbrich, I. M., Zhang, Q., Cappa, C. D., Ziemann, P. J., and Jimenez, J. L.: Evaluation of recently-proposed secondary organic aerosol models for a case study in Mexico City, Atmos. Chem. Phys., 9, 5681-5709, doi:10.5194/acp-9-5681-2009, 2009.

Edgerton, S. A., Bian, X., Doran, J. C., et al.: Particulate air pollution in Mexico City: A collaborative research project, J. Air Waste Manage., 49, 1221-1229, 1999.

Fast, J., Aiken, A. C., Allan, J., Alexander, L., Campos, T., Canagaratna, M. R., Chapman, E., DeCarlo, P. F., de Foy, B., Gaffney, J., de Gouw, J., Doran, J. C., Emmons, L., Hodzic, A., Herndon, S. C., Huey, G., Jayne, J. T., Jimenez, J. L., Kleinman, L., Kuster, W., Marley, N., Russell, L., Ochoa, C., Onasch, T. B., Pekour, M., Song, C., Ulbrich, I. M., Warneke, C., WelshBon, D., Wiedinmyer, C., Worsnop, D. R., Yu, X.-Y., and Zaveri, R.: Evaluating simulated primary anthropogenic and biomass burning organic aerosols during MILAGRO: implications for assessing treatments of secondary organic aerosols, Atmos. Chem. Phys., 9, 6191-6215, doi:10.5194/acp-9-6191-2009, 2009.

Fast, J. D., de Foy, B., Acevedo Rosas, F., Caetano, E., Carmichael, G., Emmons, L., McKenna, D., Mena, M., Skamarock, W., Tie, X., Coulter, R. L., Barnard, J. C., Wiedinmyer, C., and Madronich, S.: A meteorological overview of the MILAGRO field campaigns, Atmos. Chem. Phys., 7, 2233-2257, doi:10.5194/acp-7-2233-2007, 2007.

Favez, O., Sciare, J., Cachier, H., et al.: Significant formation of water-insoluble secondary organic aerosols in semiarid urban environment, Geophys. Res. Lett., 35, L015801, doi:10.1029/2008GL034446, 2008.

Giglio, L., Descloitres, J., Justice, C. O., et al.: An enhanced contextual fire detection algorithm for MODIS, Remote Sens. Environ., 87, 273-282, 2003.

Gilardoni, S., Liu, S., Takahama, S., Russell, L. M., Allan, J. D., Steinbrecher, R., Jimenez, J. L., De Carlo, P. F., Dunlea, E. J., and Baumgardner, D.: Characterization of organic ambient aerosol during MIRAGE 2006 on three platforms, Atmos. Chem. Phys., 9, 5417-5432, doi:10.5194/acp-9-5417-2009, 2009.

Graham, B., Mayol-Bracero, O. L., Guyon, P., et al.: Water-soluble organic compounds in biomass burning aerosols over Amazonia - 1. Characterization by NMR and GC-MS, J. Geo-phys. Res.Atmos., 107, 8047, doi:10.1029/2001JD000336, 2002.

Grieshop, A. P., Donahue, N. M., and Robinson, A. L.: Laboratory investigation of photochemical oxidation of organic aerosol from wood fires 2: analysis of aerosol mass spectrometer data, Atmos. Chem. Phys., 9, 2227-2240, doi:10.5194/acp-9-2227-2009, 2009.

Hallquist, M., Wenger, J. C., Baltensperger, U., Rudich, Y., Simpson, D., Claeys, M., Dommen, J., Donahue, N. M., George, C., Goldstein, A. H., Hamilton, J. F., Herrmann, H., Hoffmann, T., Iinuma, Y., Jang, M., Jenkin, M. E., Jimenez, J. L., KiendlerScharr, A., Maenhaut, W., McFiggans, G., Mentel, T. F., Monod, A., Prévôt, A. S. H., Seinfeld, J. H., Surratt, J. D., Szmigiel- ski, R., and Wildt, J.: The formation, properties and impact of secondary organic aerosol: current and emerging issues, Atmos. Chem. Phys., 9, 5155-5236, doi:10.5194/acp-9-5155-2009, 2009.

Heald, C. L. and Spracklen, D. V. Atmospheric budget of primary biological aerosol particles from fungal spores, Geophys. Res. Lett., 36, L09806, doi:10.1029/2009GL037493, 2009.

Heald, C. L., Kroll, J. H., Jimenez, J. L., et al.: A simplified description of organic aerosol composition and implications for atmospheric aging, Geophys. Res. Lett., 37, L08803, doi:10.1029/2010GL042737, 2010.

Hennigan, C. J., Sullivan, A. P., Fountoukis, C. I., Nenes, A., Hecobian, A., Vargas, O., Peltier, R. E., Case Hanks, A. T., Huey, L. G., Lefer, B. L., Russell, A. G., and Weber, R. J.: On the volatility and production mechanisms of newly formed nitrate and water soluble organic aerosol in Mexico City, Atmos. Chem. Phys., 8, 3761-3768, doi:10.5194/acp-8-3761-2008, 2008.

Hennigan, C. J., Sullivan, A. P., Collett, J. L., and Robinson, A. L.: Levoglucosan stability in biomass burning particles exposed to hydroxyl radicals, Geophys. Res. Lett., 37, L09806, doi:10.1029/2010GL043088, 2010.

Herndon, S. C., Onasch, T. B., Wood, E. C., et al.: The Correlation of Secondary Organic Aerosol with Odd Oxygen in a Megacity Outflow, Geophys. Res. Lett., 35, L15804, doi:10.1029/2008GL034058, 2008.

Hildemann, L. M., Klinedinst, D. B., Klouda, G. A., et al.: Sources of Urban Contemporary Carbon Aerosol, Environ. Sci. Technol., 28, 1565-1576, 1994.

Hildemann, L. M., Markowski, G. R., and Cass, G. R.: Chemicalcomposition of emissions from urban sources of fine organic aerosol, Environ. Sci. Technol., 25, 744-759, 1991.

Hodzic, A., Jimenez, J. L., Madronich, S., Aiken, A. C., Bessagnet, B., Curci, G., Fast, J., Lamarque, J.-F., Onasch, T. B., Roux, G., Schauer, J. J., Stone, E. A., and Ulbrich, I. M.: Modeling organic aerosols during MILAGRO: importance of biogenic secondary organic aerosols, Atmos. Chem. Phys., 9, 6949-6981, doi:10.5194/acp-9-6949-2009, 2009.

Hodzic, A., Jimenez, J. L., Madronich, S., Canagaratna, M. R., DeCarlo, P. F., Kleinman, L., and Fast, J.: Potential contribution of semi-volatile and intermediate volatility primary organic compounds to secondary organic aerosol in the Mexico City region, Atmos. Chem. Phys. Discuss., 10, 657-710, doi:10.5194/acpd10-657-2010, 2010.

Hudson, P. K., Murphy, D. M., Cziczo, D. J., et al.: Biomass-burning particle measurements: Characteristic composition and chemical processing, J. Geophys. Res.-Atmos. 109, doi:10.1029/2003JD004398, D004323S004327, 2004.

Huffman, J. A., Docherty, K. S., Aiken, A. C., Cubison, M. J., Ulbrich, I. M., DeCarlo, P. F., Sueper, D., Jayne, J. T., Worsnop, D. R., Ziemann, P. J., and Jimenez, J. L.: Chemically-resolved aerosol volatility measurements from two megacity field studies, Atmos. Chem. Phys., 9, 7161-7182, doi:10.5194/acp-9-71612009, 2009.

IPCC: Climate Change 2007 - The Physical Science Basis. Working Group I Contribution to the Fourth Assessment Report of the IPCC, Cambridge, UK, Cambridge University Press, 2007.

Jimenez, J. L., Canagaratna, M. R., Donahue, N. M., et al.: Evolution of Organic Aerosols in the Atmosphere, Science, 326, 15251529, 2009. 
Johnson, K. S., de Foy, B., Zuberi, B., Molina, L. T., Molina, M. J., Xie, Y., Laskin, A., and Shutthanandan, V.: Aerosol composition and source apportionment in the Mexico City Metropolitan Area with PIXE/PESA/STIM and multivariate analysis, Atmos. Chem. Phys., 6, 4591-4600, doi:10.5194/acp-6-4591-2006, 2006.

Justice, C. O., Giglio, L., Korontzi, S., et al.: The MODIS fire products, Remote Sens. Environ., 83, 244-262, 2002.

Karl, T., Apel, E., Hodzic, A., Riemer, D. D., Blake, D. R., and Wiedinmyer, C.: Emissions of volatile organic compounds inferred from airborne flux measurements over a megacity, Atmos. Chem. Phys., 9, 271-285, doi:10.5194/acp-9-271-2009, 2009.

Kleinman, L. I., Springston, S. R., Daum, P. H., Lee, Y.-N., Nunnermacker, L. J., Senum, G. I., Wang, J., Weinstein-Lloyd, J., Alexander, M. L., Hubbe, J., Ortega, J., Canagaratna, M. R., and Jayne, J.: The time evolution of aerosol composition over the Mexico City plateau, Atmos. Chem. Phys., 8, 1559-1575, doi:10.5194/acp-8-1559-2008, 2008.

Knighton, W. B., Fortner, E. C., Herndon, S. C., et al.: Examination of biomass burning tracer signatures in urban environments. EOS Trans. AGU. Abstract A33D-1569, Fall Meet. Suppl. 88, 2007.

Kondo, Y., Miyazaki, Y., Takegawa, N., et al.: Oxygenated and water-soluble organic aerosols in Tokyo, J. Geophys. Res.Atmos., 112, D01203, doi:10.1029/2006JD007056, 2007.

Lanz, V. A., Alfarra, M. R., Baltensperger, U., Buchmann, B., Hueglin, C., and Prvt, A. S. H.: Source apportionment of submicron organic aerosols at an urban site by factor analytical modelling of aerosol mass spectra, Atmos. Chem. Phys., 7, 15031522, doi:10.5194/acp-7-1503-2007, 2007.

Lawrence, M. G., Butler, T. M., Steinkamp, J., Gurjar, B. R., and Lelieveld, J.: Regional pollution potentials of megacities and other major population centers, Atmos. Chem. Phys., 7, 39693987, doi:10.5194/acp-7-3969-2007, 2007.

Lee, D. S. and Pacyna, J. M.: An industrial emissions inventory of calcium for Europe, Atmos. Environ. 33, 1687-1697, 1999.

Lee, S., Baumann, K., Schauer, J. J., et al.: Gaseous and Particulate Emissions from Prescribed Burning in Georgia, Environ. Sci. Technol., 29, 9049-9056, 2005.

Likens, G. E., Driscoll, C. T., and Buso, D. C.: Long-term effects of acid rain: Response and recovery of a forest ecosystem, Science, 272(5259), 244-246, 1996.

Liu, S., Takahama, S., Russell, L. M., Gilardoni, S., and Baumgardner, D.: Oxygenated organic functional groups and their sources in single and submicron organic particles in MILAGRO 2006 campaign, Atmos. Chem. Phys., 9, 6849-6863, doi:10.5194/acp9-6849-2009, 2009.

Madronich, S.: Chemical evolution of gaseous air pollutants downwind of tropical megacities: Mexico City case study, Atmos. Environ., 40, 6012-6018, 2006.

Marley, N. A., Gaffney, J. S., Tackett, M., Sturchio, N. C., Heraty, L., Martinez, N., Hardy, K. D., Marchany-Rivera, A., Guilderson, T., MacMillan, A., and Steelman, K.: The impact of biogenic carbon sources on aerosol absorption in Mexico City, Atmos. Chem. Phys., 9, 1537-1549, doi:10.5194/acp-9-1537-2009, 2009.

Moffet, R. C., de Foy, B., Molina, L. T., Molina, M. J., and Prather, K. A.: Measurement of ambient aerosols in northern Mexico City by single particle mass spectrometry, Atmos. Chem. Phys., 8, 4499-4516, doi:10.5194/acp-8-4499-2008, 2008a.
Moffet, R. C., Desyaterik, Y., Hopkins, R. J., et al.: Characterization of Aerosols Containing $\mathrm{Zn}, \mathrm{Pb}$, and $\mathrm{Cl}$ from an Industrial Region of Mexico City, Environ. Sci. Technol., 42, 7091-7097, 2008b.

Mohr, C., Huffman, J. A., Cubison, M. J., et al.: Characterization of primary organic aerosol emissions from meat cooking, trash burning, and motor vehicles with high-resolution aersol mass spectrometry and comparison with ambient and chamber observations, Environ. Sci. Technol. 43, 2443-2449, doi:2410.1021/es8011518, 2009.

Molina, L. T., Kolb, C. E., de Foy, B., Lamb, B. K., Brune, W. H., Jimenez, J. L., Ramos-Villegas, R., Sarmiento, J., ParamoFigueroa, V. H., Cardenas, B., Gutierrez-Avedoy, V., and Molina, M. J.: Air quality in North America's most populous city overview of the MCMA-2003 campaign, Atmos. Chem. Phys., 7, 2447-2473, doi:10.5194/acp-7-2447-2007, 2007.

Molina, L. T., Madronich, S., Gaffney, J. S., Apel, E., de Foy, B., Fast, J., Ferrare, R., Herndon, S., Jimenez, J. L., Lamb, B., Osornio-Vargas, A. R., Russell, P., Schauer, J. J., Stevens, P. S., and Zavala, M.: An overview of the MILAGRO 2006 campaign: Mexico City emissions and their transport and transformation, Atmos. Chem. Phys. Discuss., 10, 7819-7983, doi:10.5194/acpd-10-7819-2010, 2010.

Moreno, T., Querol, X., Pey, J., et al.: Spatial and temporal variations in inhalable $\mathrm{CuZnPb}$ aerosols within the Mexico City pollution plume, J. Environ. Monitor., 10, 370-378, 2008.

Nemitz, E., Jimenez, J. L., Huffman, J. A., et al.: An eddycovariance system for the measurement of surface/atmosphere exchange fluxes of submicron aerosol chemical species - First application above an urban area, Aerosol Sci. Tech 42, 636-657, 2008.

Ng, N. L., Canagaratna, M. R., Zhang, Q., Jimenez, J. L., Tian, J., Ulbrich, I. M., Kroll, J. H., Docherty, K. S., Chhabra, P. S., Bahreini, R., Murphy, S. M., Seinfeld, J. H., Hildebrandt, L., Donahue, N. M., DeCarlo, P. F., Lanz, V. A., Prvt, A. S. H., Dinar, E., Rudich, Y., and Worsnop, D. R.: Organic aerosol components observed in Northern Hemispheric datasets from Aerosol Mass Spectrometry, Atmos. Chem. Phys., 10, 46254641, doi:10.5194/acp-10-4625-2010, 2010.

Paredes-Miranda, G., Arnott, W. P., Jimenez, J. L., Aiken, A. C., Gaffney, J. S., and Marley, N. A.: Primary and secondary contributions to aerosol light scattering and absorption in Mexico City during the MILAGRO 2006 campaign, Atmos. Chem. Phys., 9, 3721-3730, doi:10.5194/acp-9-3721-2009, 2009.

Querol, X., Pey, J., Minguilln, M. C., Pérez, N., Alastuey, A., Viana, M., Moreno, T., Bernabé, R. M., Blanco, S., Cárdenas, B., Vega, E., Sosa, G., Escalona, S., Ruiz, H., and Artano, B.: PM speciation and sources in Mexico during the MILAGRO-2006 Campaign, Atmos. Chem. Phys., 8, 111-128, doi:10.5194/acp-8-1112008, 2008.

Raga, G. B., Baumgardner, D., Castro, T., et al.: Mexico City air quality: a qualitative review of gas and aerosol measurements (1960-2000), Atmos. Environ., 35, 4041-4058, 2001.

Reid, J. S., Koppmann, R., Eck, T. F., and Eleuterio, D. P.: A review of biomass burning emissions part II: intensive physical properties of biomass burning particles, Atmos. Chem. Phys., 5, 799825, doi:10.5194/acp-5-799-2005, 2005.

Rivera, C., Sosa, G., Whrnschimmel, H., de Foy, B., Johansson, M., and Galle, B.: Tula industrial complex (Mexico) emissions of $\mathrm{SO}_{2}$ and $\mathrm{NO}_{2}$ during the MCMA 2006 field campaign using a 
mobile mini-DOAS system, Atmos. Chem. Phys., 9, 6351-6361, doi:10.5194/acp-9-6351-2009, 2009.

Ruff, M., Gaggeler, H. W., Suter, M., et al.: Gaseous radiocarbon measurements of small samples, Nucl. Instr. Meth. Phys. Res. B, 268, 790-794, doi:10.1016/j.nimb.2009.10.032, 2010.

Ruff, M., Wacker, L., Gaggeler, H. W., et al.: A gas ion source for radiocarbon measurements at $200 \mathrm{kV}$, Radiocarbon, 49, 307-314, 2007.

Saarikoski, S., Sillanpaa, M., Sofiev, M., et al.: Chemical composition of aerosols during a major biomass burning episode over northern Europe in spring 2006: Experimental and modelling assessments, Atmos. Environ., 41, 3577-3589, 2007.

Salcedo, D., Onasch, T. B., Dzepina, K., Canagaratna, M. R., Zhang, Q., Huffman, J. A., DeCarlo, P. F., Jayne, J. T., Mortimer, P., Worsnop, D. R., Kolb, C. E., Johnson, K. S., Zuberi, B., Marr, L. C., Volkamer, R., Molina, L. T., Molina, M. J., Cardenas, B., Bernab, R. M., Márquez, C., Gaffney, J. S., Marley, N. A., Laskin, A., Shutthanandan, V., Xie, Y., Brune, W., Lesher, R., Shirley, T., and Jimenez, J. L.: Characterization of ambient aerosols in Mexico City during the MCMA-2003 campaign with Aerosol Mass Spectrometry: results from the CENICA Supersite, Atmos. Chem. Phys., 6, 925-946, doi:10.5194/acp-6-9252006, 2006.

Sannigrahi, P., Sullivan, A. P., Weber, R. J., et al.: Characterization of water-soluble organic carbon in urban atmospheric aerosols using solid-state C-13 NMR spectroscopy, Environ. Sci. Technol., 40, 666-672, 2006.

Schauer, J. J., Kleeman, M. J., Cass, G. R., et al.: Measurement of emissions from air pollution sources, 1. C-1 through C-29 organic compounds from meat charbroiling, Environ. Sci. Technol., 33, 1566-1577, 1999.

Schroeder, W., Csiszar, I., and Morisette, J.: Quantifying the impact of cloud obscuration on remote sensing of active fires in the Brazilian Amazon, Remote Sens. Environ., 112, 456-470, 2008.

Shaw, W. J., Pekour, M. S., Coulter, R. L., Martin, T. J., and Walters, J. T.: The daytime mixing layer observed by radiosonde, profiler, and lidar during MILAGRO, Atmos. Chem. Phys. Discuss., 7, 15025-15065, doi:10.5194/acpd-7-15025-2007, 2007.

Sheesley, R. J., Schauer, J. J., Chowdhury, Z., et al.: Characterization of organic aerosols emitted from the combustion of biomass indigenous to South Asia, J. Geophys. Res., 108, 4285, doi:10.1029/2002JD002981, 2003.

Skamarock, W. C., Klemp, J. B., Dudhia, J., et al.: A description of the advanced research WRF verison 2. NCAR Technical Note, 2005.

SMA, Secretaria del Medio Ambiente, G. D. D. F.: Inventario de Emisiones, http://www.sma.df.gob.mx/inventarioemisiones/, 2006.

Stohl, A., Forster, C., Frank, A., Seibert, P., and Wotawa, G.: Technical note: The Lagrangian particle dispersion model FLEXPART version 6.2, Atmos. Chem. Phys., 5, 2461-2474, doi:10.5194/acp-5-2461-2005, 2005.

Stone, E. A., Hedman, C. J., Zhou, J., et al.: Insights into the nature of secondary organic aerosol in Mexico City during the MILAGRO experiment 2006, Atmos. Environ., 44, 312-319, doi:10.1016/j.atmosenv.2009.1010.1036, 2009.

Stone, E. A., Snyder, D. C., Sheesley, R. J., Sullivan, A. P., Weber, R. J., and Schauer, J. J.: Source apportionment of fine organic aerosol in Mexico City during the MILAGRO experiment
2006, Atmos. Chem. Phys., 8, 1249-1259, doi:10.5194/acp-81249-2008, 2008.

Sullivan, A. P., Holden, A. S., Patterson, L. A., et al.: A method for smoke marker measurements and its potential application for determining the contribution of biomass burning from wildfires and prescribed fires to ambient $\mathrm{PM}_{2.5}$ organic carbon, J. Geophys. Res.-Atmos. 113, D22302, doi:22310.21029/22008JD010216, 2008.

Szidat, S., Jenk, T. M., Gaggeler, H. W., et al.: Source apportionment of aerosols by C-14 measurements in different carbonaceous particle fractions, Radiocarbon, 46, 475-484, 2004a.

Szidat, S., Jenk, T. M., Gaggeler, H. W., et al.: THEODORE, a two-step heating system for the EC/OC determination of radiocarbon (C-14) in the environment, Nucl. Instrum. Meth. B., 22324, 829-836, 2004b.

Szidat, S., Jenk, T. M., Synal, H. A., et al.: Contributions of fossil fuel, biomass-burning, and biogenic emissions to carbonaceous aerosols in Zurich as traced by C-14, J. Geophys. Res.-Atmos., 111, D007206, doi:10.1029/2005JD006590, 2006.

Szidat, S., Ruff, M., Perron, N., Wacker, L., Synal, H.-A., Hallquist, M., Shannigrahi, A. S., Yttri, K. E., Dye, C., and Simpson, D.: Fossil and non-fossil sources of organic carbon (OC) and elemental carbon (EC) in Gteborg, Sweden, Atmos. Chem. Phys., 9, 1521-1535, doi:10.5194/acp-9-1521-2009, 2009.

Tsimpidi, A. P., Karydis, V. A., Zavala, M., Lei, W., Molina, L., Ulbrich, I. M., Jimenez, J. L., and Pandis, S. N.: Evaluation of the volatility basis-set approach for the simulation of organic aerosol formation in the Mexico City metropolitan area, Atmos. Chem. Phys., 10, 525-546, doi:10.5194/acp-10-525-2010, 2010.

Ulbrich, I. M., Canagaratna, M. R., Zhang, Q., Worsnop, D. R., and Jimenez, J. L.: Interpretation of organic components from Positive Matrix Factorization of aerosol mass spectrometric data, Atmos. Chem. Phys., 9, 2891-2918, doi:10.5194/acp-9-2891-2009, 2009.

Vay, S. A., Tyler, S. C., Choi, Y., Blake, D. R., Blake, N. J., Sachse, G. W., Diskin, G. S., and Singh, H. B.: Sources and transport of $\triangle 14 \mathrm{C}$ in $\mathrm{CO}_{2}$ within the Mexico City Basin and vicinity, Atmos. Chem. Phys., 9, 4973-4985, doi:10.5194/acp-9-4973-2009, 2009.

Vega, E., Reyes, E., Ruiz, H., et al.: Analysis of $\mathrm{PM}_{2.5}$ and $\mathrm{PM}_{10}$ in the Atmosphere of Mexico City during 2000-2002, J. Air Waste Manage., 54, 786-798, 2004.

Velasco, E., Lamb, B., Westberg, H., Allwine, E., Sosa, G., ArriagaColina, J. L., Jobson, B. T., Alexander, M. L., Prazeller, P., Knighton, W. B., Rogers, T. M., Grutter, M., Herndon, S. C., Kolb, C. E., Zavala, M., de Foy, B., Volkamer, R., Molina, L. T., and Molina, M. J.: Distribution, magnitudes, reactivities, ratios and diurnal patterns of volatile organic compounds in the Valley of Mexico during the MCMA 2002 \& 2003 field campaigns, Atmos. Chem. Phys., 7, 329-353, doi:10.5194/acp-7-329-2007, 2007.

Volkamer, R., Jimenez, J. L., San Martini, F., et al.: Secondary organic aerosol formation from anthropogenic air pollution: Rapid and higher than expected, Geophys Res. Lett., 33, L17811, doi:17810.11029/12006GL026899, 2006.

Volkamer, R., Martini, F. S., Molina, L. T., et al.: A missing sink for gas-phase glyoxal in Mexico City: Formation of secondary organic aerosol, Geophys Res. Lett., 34, L19807, doi:10.1029/2007GL030752, 2007. 
Watson, J. G. Visibility: Science and Regulation, J. Air Waste Manage., 52, 628-713, 2002.

Weber, R. J., Sullivan, A. P., Peltier, R. E., et al.: A study of secondary organic aerosol formation in the anthropogenicinfluenced southeastern United States, J. Geophys. Res.-Atmos., 112, D13302, doi:10.1029/2007JD008408, 2007.

Wiedinmyer, C., Quayle, B., Geron, C., et al.: Estimating emissions from fires in North America for air quality modeling, Atmos. Environ., 40, 3419-3432, 2006.

Wöhrnschimmel, H., Magaa, M., Stahel, W. A., Blanco, S., Acuña, S., Pérez, J. M., González, S., Gutiérrez, V., Wakamatsu, S., and Cárdenas, B.: Measurements and receptor modeling of volatile organic compounds in south-eastern Mexico City, 2000-2007, Atmos. Chem. Phys. Discuss., 10, 3319-3346, doi:10.5194/acpd-10-3319-2010, 2010.

Yokelson, R. J., Crounse, J. D., DeCarlo, P. F., Karl, T., Urbanski, S., Atlas, E., Campos, T., Shinozuka, Y., Kapustin, V., Clarke, A. D., Weinheimer, A., Knapp, D. J., Montzka, D. D., Holloway, J., Weibring, P., Flocke, F., Zheng, W., Toohey, D., Wennberg, P. O., Wiedinmyer, C., Mauldin, L., Fried, A., Richter, D., Walega, J., Jimenez, J. L., Adachi, K., Buseck, P. R., Hall, S. R., and Shetter, R.: Emissions from biomass burning in the Yucatan, Atmos. Chem. Phys., 9, 5785-5812, doi:10.5194/acp-9-5785-2009, 2009.
Yokelson, R. J., Urbanski, S. P., Atlas, E. L., Toohey, D. W., Alvarado, E. C., Crounse, J. D., Wennberg, P. O., Fisher, M. E., Wold, C. E., Campos, T. L., Adachi, K., Buseck, P. R., and Hao, W. M.: Emissions from forest fires near Mexico City, Atmos. Chem. Phys., 7, 5569-5584, doi:10.5194/acp-7-5569-2007, 2007.

Zhang, Q., Alfarra, M. R., Worsnop, D. R., et al.: Deconvolution and quantification of hydrocarbon-like and oxygenated organic aerosols based on aerosol mass spectrometry, Environ. Sci. Technol., 39, 4938-4952, 2005a.

Zhang, Q., Worsnop, D. R., Canagaratna, M. R., and Jimenez, J. L.: Hydrocarbon-like and oxygenated organic aerosols in Pittsburgh: insights into sources and processes of organic aerosols, Atmos. Chem. Phys., 5, 3289-3311, doi:10.5194/acp-5-32892005, 2005 b.

Zhang, Q., Jimenez, J. L., Worsnop, D. R., et al.: A case study of urban particle acidity and its influence on secondary organic aerosol, Environ. Sci. Technol., 41, 3213-3219, 2007.

Zheng, M., Ke, L., Edgerton, E. S., et al.: Spatial distribution of carbonaceous aerosol in the southeastern United States using molecular markers and carbon isotope data, J. Geophys. Res.-Atmos., 111, D006710S006706, doi:10.1029/2005JD006777, 2006. 